Article

\title{
Assessing Supply Chain Risks in the Automotive Industry through a Modified MCDM-Based FMECA
}

\author{
Ilyas Mzougui ${ }^{1}$, Silvia Carpitella ${ }^{2} \oplus$, Antonella Certa ${ }^{2}$, Zoubir El Felsoufi ${ }^{1}$ and \\ Joaquín Izquierdo $3, *$ (D) \\ 1 Faculty of Sciences and Technologies, Abdelmalek Essaadi University, Tangier 93030, Morocco; \\ ilyas.mzougui@gmail.com (I.M.); elfelsoufi_zoubir@yahoo.fr (Z.E.F.) \\ 2 Department of Engineering, University of Palermo, 90133 Palermo, Italy; silvia.carpitella@unipa.it (S.C.); \\ antonella.certa@unipa.it (A.C.) \\ 3 Institute for Multidisciplinary Mathematics, Universitat Politècnica de València, 46022 Valencia, Spain \\ * Correspondence: jizquier@upv.es; Tel.: +34-628-028-804
}

Received: 1 April 2020; Accepted: 9 May 2020; Published: 13 May 2020

\begin{abstract}
Supply chains are complex networks that receive assiduous attention in the literature. Like any complex network, a supply chain is subject to a wide variety of risks that can result in significant economic losses and negative impacts in terms of image and prestige for companies. In circumstances of aggressive competition among companies, effective management of supply chain risks (SCRs) is crucial, and is currently a very active field of research. Failure Mode, Effects and Criticality Analysis (FMECA) has been recently extended to SCR identification and prioritization, aiming at reducing potential losses caused by lack of risk control. This article has a twofold objective. First, SCR assessment is investigated, and a comprehensive list of specific risks related to the automotive industry is compiled to extend the set of most commonly considered risks. Second, an alternative way of calculating the Risk Priority Number (RPN) is proposed within the FMECA framework by means of an integrated Multi-Criteria Decision-Making (MCDM) approach. We give a new calculation procedure by making use of the Analytic Hierarchy Process (AHP) to derive factors weights, and then the fuzzy Decision-Making Trial and Evaluation Laboratory (DEMATEL) to evaluate the new factor of "dependence" among the risks. The developed joint analysis constitutes a risk analysis support tool for criticality in systems engineering. The approach also deals with uncertainty and vagueness associated with input data through the use of fuzzy numbers. The results obtained from a relevant case study in the automotive industry showcase the effectiveness of this approach, which brings important value to those companies: When planning interventions of prevention/mitigation, primary importance should be given to (1) supply chain disruptions due to natural disasters; (2) manufacturing facilities, human resources, policies and breakdown processes; and (3) inefficient transport.
\end{abstract}

Keywords: supply chain; criticality and risk analysis; systems engineering; FMECA; AHP; fuzzy DEMATEL

\section{Introduction}

Nowadays competition among enterprises is evolving from a classical mere production-oriented task towards a more complex concept involving supply chain (SC) management. The first study about the need of enhancing competitiveness was led by Porter in 1985 [1]. In this context, companies' efforts often tend to focus on improving supply chain efficiency without paying due attention to the possible occurrence of significant risks of supply chain disruption, whose magnitude may be reduced by making effective decisions on reconfiguration of manufacturing systems and supply chains [2]. 
If, on the one hand, this condition aims to reduce operational costs and improve profitability, on the other hand, vulnerability of enterprises may considerably increase under the point of view of supply chain security. Munir et al. [3] claim that organizations are increasingly subjected to unpredictable events of disruptions, globally affecting supply chains. In this respect, the authors provide as examples the fire that occurred at the Philips plant in 2000 that affected both the companies Nokia and Ericsson, disrupting their supply chains, as well as the quadruple disasters that affected Japan in 2011, leading to disruptions in global supply chains.

Despite their existence, many risks may be prevented just by better structuring the decision-making processes and by adopting models of supply chain management to enhance service levels [4]. Specifically, as underlined by Garvey and Carnovale [5], apart from the potential risks strictly related to supply chains, the effects of their propagation throughout the whole networks should be considered. Kern et al. [6] affirm that failures involving supply chains cause a loss of around USD $\$ 100$ million per day in the field of automotive industry. It is then clear the importance of taking into proper consideration the risks in supply chain management, with a special focus on the complexity of the structure of the supply chain network, which, according to [7], is one of the main reasons leading to supply chain interruption risks.

The research developed in this paper is aimed at (1) investigating the field of supply chain risk (SCR) assessment to elaborate a comprehensive list of risks related to the automotive industry, as a contribution to the current state of the art; and (2) proposing a novel calculation method instead of the Risk Priority Number (RPN) used by traditional methodologies, such as Failure Modes, Effects and Criticality Analysis (FMECA), for estimating the criticality of the risks. Specifically, such a novel calculation makes use of four factors (in contrast with the traditional three of severity, occurrence and detectability) to improve FMECA analyses in the SC field by means of an integrated Multi-Criteria Decision-Making (MCDM) approach. This approach proposes the use of the application of the Analytic Hierarchy Process (AHP) to evaluate the mutual importance of the chosen factors, and the fuzzy Decision-Making Trial and Evaluation Laboratory (DEMATEL) to numerically evaluate one of the new introduced factors, called "dependence", characterizing each risk as a partial expression of severity. We claim that such a hybrid MCDM-based approach is a useful risk assessment tool for criticality and risk analysis in systems engineering and, in particular, is suitable to tackle SCR management since it is capable of managing the uncertainty and vagueness affecting the input evaluations provided by the experts. A case study in the automotive industry, a paradigmatic industry in systems engineering, is eventually implemented to elaborate the final ranking of the SCRs affecting this field, and to test the applicability and effectiveness of the approach.

The paper is organized as follows. Section 2 presents a literature review about SCR assessment and MCDM approaches, and proposes a new list of risks related to the automotive industry. Section 3 describes the modification implemented within the FMECA framework and the methodologies used in the present research. A practical application, together with a suitable sensitivity analysis, is developed in Section 4. Lastly, the conclusions in Section 5 close the work.

\section{Literature Review and New Contribution to the Automotive Industry}

\subsection{FMECA-Based Assessment of Supply Chain Risks}

Regarding SCR assessment, the existing literature started to face this problem first in terms of risks categorization. For instance, Ghoshal [8] identifies four main categories of risk, namely, macroeconomic risk, policy risk, competitive risk and resource risk. Schoenherr et al. [9] identify other nine categories: demand risk, delay risk, disruption risk, inventory risk, manufacturing (process) breakdown risk, physical plant (capacity) risk, supply (procurement) risk, system risk, sovereignty risk and transportation risk. Apart from the mentioned categories, sustainability risks should be considered as well, since they are progressively becoming increasingly relevant for many industries [10].

Curkovic et al. [11] underline that analyses performed by methodologies such as Failure Mode and Effect Analysis (FMEA) and Failure Modes, Effects and Criticality Analysis (FMECA) [12], 
provide substantial benefits in evaluating risks, globally improving the performance level of a supply chain. Tang and Tomlin [13] analyzed supply chain risks by means of a FMEA-based approach in order to contribute to a collaborative environment, integrating an adapted action plan for risk prevention. According to Ghadge et al. [14], FMEA helps improve product quality and delivery performance by proactively identifying and mitigating risks. The authors also affirm that incorporating elements of fuzzy theory within the FMEA framework provides a robust preventive method of supply chain risk (SCR) assessment.

Given the usefulness of the FMEA-based approach, the first objective of the present paper will be pursued by assuming a FMEA/FMECA perspective to provide a state-of-the-art contribution in the field of the automotive industry and produce a new comprehensive list of the main related SCRs. To the best of the authors' knowledge, such an analysis has not been led so far in the literature.

Once we have compiled the list of SCRs, the second objective of the paper will be achieved by proposing a modified calculation of the traditional Risk Priority Number (RPN) - the typical parameter used in FMECA analyses-for ranking the identified risks, leading to establish priorities of intervention. Specifically, we make use of various calculation factors, which differ from the traditional ones, through the support of a Multi-Criteria Decision-Making (MCDM) approach.

\subsection{Multi-Criteria Decision-Making Methods}

A wide variety of MCDM methods with important applications can be found in the literature. Among them, the most commonly used [15] is certainly the Analytic Hierarchy Process (AHP), originally developed by Saaty [16], which calculates criteria priority vectors and rank alternatives. AHP can be applied to virtually any field, such as water supply [17] and environment management [18], among many others. Moreover, the literature [19,20] supports the integration of AHP with other MCDM techniques to make the final results more trustworthy. A straightforward application of $\mathrm{AHP}$, as done in this paper, can easily weight the various factors involved in the calculation of the modified RPN.

Regarding the choice of the criteria involved in the RPN calculation, we are mainly interested in evaluating risks by studying their degree of interdependence, since the occurrence of one or more of them may cause the occurrence of others. According to Govindan [21], the complexity of analyzing the logistics field is often due to the presence of various risks with multiple interrelationships, and these interdependencies need to be carefully studied in order to develop an effective risk analysis. To deal with this problem, Lee et al. [22] propose the use of the Decision-Making Trial and Evaluation Laboratory (DEMATEL) for analyzing the interrelationships and interdependencies by neglecting the limitations derived from the sample size. The DEMATEL method was initially proposed by Gabus and Fontela $[23,24]$ to identify influential strengths among complicated issues, such as racial discrimination, labor protection, hunger, race, and so on. DEMATEL has also been integrated with other MCDM techniques [25], and widely used in the literature to tackle SCRs.

However, despite its wide application, authors such as Naderikia and Nazeri [26] criticize DEMATEL because of the use of crisp values, since this may compromise the effectiveness of results. The fuzzy extension of the method seems to be more appropriate. It permits to deal with uncertainty affecting human evaluations and may improve FMEA and FMECA applications [27].

The fuzzy DEMATEL method has been successfully applied in the literature to support various types of decision-making problems. For instance, Muhammad and Cavus [28] evaluated the relationships among twelve criteria related to learning management systems. Chang et al. [29] applied the fuzzy DEMATEL to find influential factors in selecting SC suppliers, by considering 10 main criteria. Govindan et al. [21] made use of the fuzzy DEMATEL to identify relationships among risks referring to third-party logistic service providers. In their study, they specifically identify 23 risks, and provide a detailed description of their likely causes and effects. 


\subsection{SCRs Classification to Identify a Specific List for the Automotive Industry}

March and Shapira [30] define SCR as a variation of expected results in terms of likelihood and subjective values. Ghadge et al. [14] provide another definition of SCR as exposure to disturbing events that negatively influence efficiency of the whole SC management. According to Blos et al. [31], SCR has to be considered as a separate topic, originating from the intersection between the processes of risk management and supply chain management.

The discipline of SCR management originates to provide solutions aimed at guaranteeing business continuous maximization. Hallikas et al. [32] structure the process of risk management through four main steps, namely, (1) risk identification; (2) risk evaluation; (3) choice and implementation of actions aimed at reducing the probability of occurrence of risks and at mitigating their severity; and (4) risk control. Schoenherr et al. [9] add two further steps to the mentioned process, namely, risk ranking and definition of acceptance thresholds.

In this paper, regarding SCR we address the steps of identification, evaluation and ranking of risks, together with definition of acceptance thresholds, as a prior step towards risk management.

Risk categories resulting from the process of risk classification are broadly known as risk sources (RSs) in the existing literature. Jüttner [33] provides the definition of RSs as those variables based on environmental, organizational or supply chain aspects that are not certainly predictable and that may consistently impact on supply chain outcomes. Authors such as Teng et al. [34] also use the definition of risk types instead of RSs to express the same concept. In any case, given the huge number and the varied nature of the possible risks characterizing operating environments, frequently related with the products and/or strategic aims of companies, it is important to get a suitable classification aimed at assigning risks to different categories on the basis of their common features. However, this type of classification directly depends on the environment under analysis. In other words, it is difficult to generalize the process of risk classification, since it has to be specifically tailored on the single industrial reality of reference. Furthermore, all the involved activities need to be carefully considered to minimize the possibility of neglecting implicit risk-related aspects.

Many kinds of risk classifications have been proposed in the literature so far, and a number of potential sources has been investigated. For instance, Jüttner et al. [35] abridge five main RSs. Taking inspiration from Sodhi et al. [36], we summarize in Table 1 some of the RSs classified in the literature in the past decade, currently considered as valid references.

Table 1. Literature review on supply chain risks (SCRs).

\begin{tabular}{|c|c|}
\hline Authors & Risks Classification \\
\hline Trent and Roberts [37] & Operational, natural disasters, terrorism or political instability, commercial or market risks. \\
\hline Bode and Wagner [38] & Demand side, supply side, regulatory, legal and bureaucratic, infrastructure, catastrophes risks. \\
\hline Tang and Tomlin [13] & Supply, process, demand, intellectual property, behavioral, political/social risks. \\
\hline Manuj and Mentzer [39] & Supply, operational, demand, security, macro, policy, competitive, resource risks. \\
\hline Jüttner [33] & Process, control, demand, supply, environmental risks. \\
\hline Schoenherr et al. [9] & $\begin{array}{l}\text { Demand, delay, disruption, inventory, manufacturing (process) breakdown, physical plant } \\
\text { (capacity), supply (procurement), system, sovereignty, transportation risks. }\end{array}$ \\
\hline Blos et al. [31] & $\begin{array}{c}\text { Water, raw material, ingredient, packaging, manufacturing process, infrastructure and natural } \\
\text { hazards, energy, environment, worker safety and health, people, skills and availability, } \\
\text { information and systems, route to market and in market, legal, legislative and regulatory, } \\
\text { workplace rights and social responsibility risks. }\end{array}$ \\
\hline Bevilacqua et al. [40,41] & $\begin{array}{l}\text { Outsourcing, product regulation, political economy, security, sustainable development, warning } \\
\text { capability, SC complexity, suppliers' complexity, transportation, terrorism, customer loyalty, } \\
\text { cyber-attack, flexibility and adaptability, other potential risk factors. }\end{array}$ \\
\hline Hsieh et al. [42] & Macro environment, extended value chain, operational, functional risks. \\
\hline Lotfi and Saghiri [43] & Risks impacting on resilience, agility and leanness. \\
\hline
\end{tabular}


Table 1. Cont.

\begin{tabular}{cr}
\hline Authors & Risks Classification \\
\hline Marasova et al. [44] & Supply, operational, demand, security, policy, competitive, resource, macro risks and other risks. \\
\hline Pandey and Sharma [45] & Risks involving supplier, logistics and handling, manufacturer, customer. \\
\hline Vujović et al. [46] & $\begin{array}{r}\text { Interruptions of working processes, delays of raw materials, malfunctioning of information } \\
\text { infrastructure, incorrect forecast, vertical integration of the PSC, uncertain supply, uncertain } \\
\text { demand, stocks of goods, flexibility and costs of capacity. }\end{array}$ \\
\hline
\end{tabular}

By analyzing Table 1, one can formulate the following considerations:

- categories describing the highlighted risk sources are extremely varied, which makes it virtually impossible to obtain a unique risk source list from the existing literature;

- risks may be related with the products and/or strategic aims of companies, as this may influence the whole risk evaluation process;

- despite some frameworks of risk classification being explicit, many others are extremely generic and risk sources change according to the needs of each activity.

With relation to the third point, the adaptation of these classifications to each specific activity is an issue of utmost importance to suitably proceed with an effective risk analysis.

Despite the impossibility of finding a unique and exhaustive agreement about SCR identification [47], we have tried to summarize the most important risks, by synthetizing the studies reported in Table 1. As a result, we have elaborated the list of risks enumerated in Table 2, mainly involving the specific reality of the automotive industry. These risks have been classified according to their type and to their primary source, and have lastly been formalized with the help of a decision-making team. In particular, the formalization process has been qualitatively implemented by means of three brainstorming sections involving four experts in the field of SC, namely a logistic manager, a quality manager, an engineering manager and an academic (a professor). The experts were invited to independently identify those risks mainly impacting on the automotive supply chain, according to their point of view. As a result of the process, the four different lists of risks compiled by the experts were merged into a unique and shared list.

Table 2. SCR identification for the automotive industry.

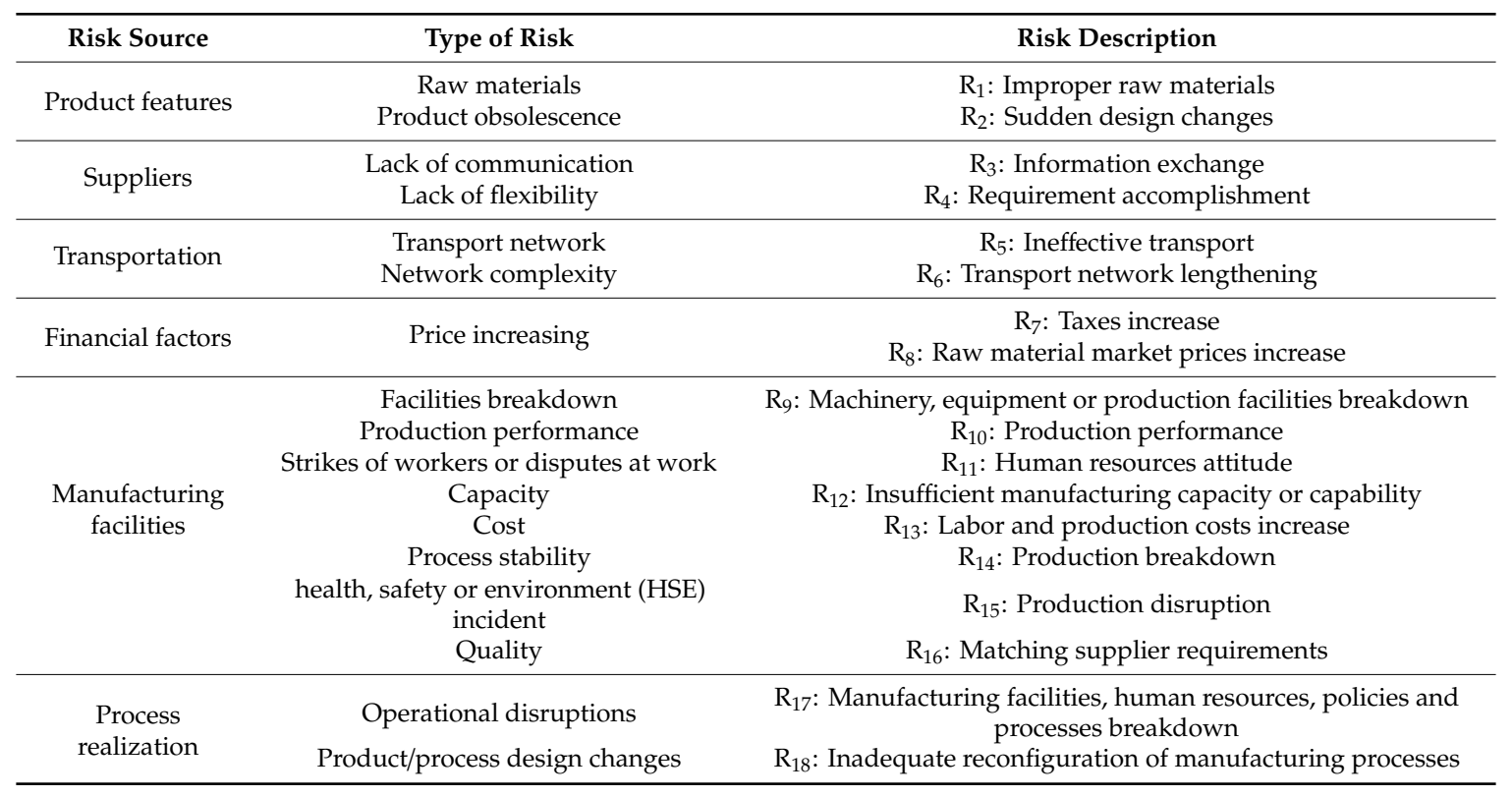


Table 2. Cont.

\begin{tabular}{ccc}
\hline Risk Source & Type of Risk & Risk Description \\
\hline Process delivery & Product delivery & $\mathrm{R}_{19}$ : Inefficient delivery of products \\
\hline \multirow{2}{*}{$\begin{array}{c}\text { External } \\
\text { environment }\end{array}$} & $\begin{array}{c}\text { Natural disasters } \\
\text { Terrorism } \\
\text { Social instability }\end{array}$ & $\mathrm{R}_{20}$ : Supply chain disruptions due to natural disasters \\
& $\mathrm{R}_{21}$ : Supply chain disruptions due to events of terrorism \\
Strategy & Supplier & $\mathrm{R}_{22}$ Social unrest in region where the supply chain operates \\
\hline
\end{tabular}

Risks listed in Table 2 hence represent the attainment of the first objective of the paper; these risks are crucial to prepare the input data for the approach herein proposed.

\section{Description of the Proposed Approach}

The final ranking of risks will be based on the value of the RPN calculated for them. As the classical way of calculation of the RPN, based on three traditional factors, has been widely criticized in the literature, we propose a different approach to perform this calculation by means of four factors, namely, $C_{1}$, occurrence; $C_{2}$, dependence; $C_{3}$, cost; and $C_{4}$, strategic impact. Since these factors may have a variable degree of importance, we also propose to calculate the AHP-based weights for these factors.

In the calculation of the RPN, various assessment processes are needed. For factors $C_{1}, C_{3}$ and $C_{4}$, direct values from a specific scale covering the entire ranges of these factors will be assigned by suitable experts, as explained latter in this section. Regarding the more complex factor $\mathrm{C}_{2}$, we propose to apply fuzzy DEMATEL to numerically evaluate the factor of dependence among the SC risks. Eventually, the obtained values of prominence will also be translated into an equivalent scale for the sake of homogeneity with the other factors' evaluations. To note, the RPN calculation is independent of the supply chain level: it may be reproduced for the original equipment manufacturer as well as for their suppliers by simultaneously guaranteeing that final results will be tailored on the specific context of application.

This will enable to calculate the new RPN for each risk. The final ranking of risks will be obtained by sorting these values decreasingly. Risks in the first positions will be those to be managed with higher priority, whereas interventions of prevention/mitigation may be postponed for the risks in the last positions.

For the sake of clarity, we underline that our approach focuses on the stage of risk evaluation in terms of criticality assessment as a fundamental important part of the whole risk management process. Aspects related to how planning/implementing measures to mitigate risks are not herein discussed.

The present section, which fully develop this process, is organized through three subsections. The description and justification of the four factors to be integrated in the modified FMECA is explained in Section 3.1, along with the formula used to calculate the new RPN. Then, the AHP and the fuzzy DEMATEL procedures are concisely presented in Sections 3.2 and 3.3.

\subsection{Modified FMECA to Identify and Assess the Main Risks}

FMEA and FMECA are systematic procedures to analyze and identify all the failure modes potentially involving a system, along with the related causes and effects. With respect to FMEA, FMECA permits to evaluate and establish a priority index for each failure mode on the basis of their values of RPN. RPN is traditionally calculated by multiplying three parameters, namely, severity (S), occurrence $(\mathrm{O})$ and detection $(\mathrm{D})$, generally ranged within the intervals $(1,5)$ or $(1,10)$. Severity expresses the intensity of the impact that the occurrence of a given failure mode could have on the global system performance; $\mathrm{O}$ is an estimate of the frequency of occurrence of the failure mode within a given time lapse; and $\mathrm{D}$ evaluates the probability of correct failure detection. In the case under analysis, all the SCRs identified and listed in Table 2 will be considered as failure modes to perform the FMECA analysis. 
Despite its easy applicability, the RPN has been widely criticized in the literature, and three main reasons emerge from the analysis of many works of research, illustrated next.

First of all, the traditional RPN calculation does not consider the differential importance of the three aforementioned parameters. Specifically, they are attributed equal weights for the RPN calculation. However, according to several studies [48-54], severity should have associated with it a higher degree of importance. The second reason refers to the mathematical formula used to calculate the RPN. Authors such as Liu et al. [55-57] and Kutlu and Ekmekçioğlu [58], for example, observe that this formula is questionable and debatable, above all because it does not consider any parameter related to costs. The third reason regard the non-continuous distribution of the values of the RPN, which makes the assessment of the differences between two consecutive values difficult $[49,56,59]$.

To these considerations, we herein add that, in the specific field of SC, using the aforementioned three parameters does not represent a suitable way to evaluate the corresponding risks with relation to all the activities. This is the reason why we aim to adjust the RPN calculation for SCRs, trying to turn it more adherent to the specific field of interest. Figure 1 analyzes the traditional FMECA parameters and all the other aspects mainly impacting on SC, which are the new parameters we propose for the RPN calculation. Criteria excluded from the present analysis are shaded, while transparent hexagons present the factors chosen to perform the RPN calculation. Choosing the suitable parameters to accomplish the RPN evaluation represents a very delicate issue [60], also related with a final modification of the same RPN equation.

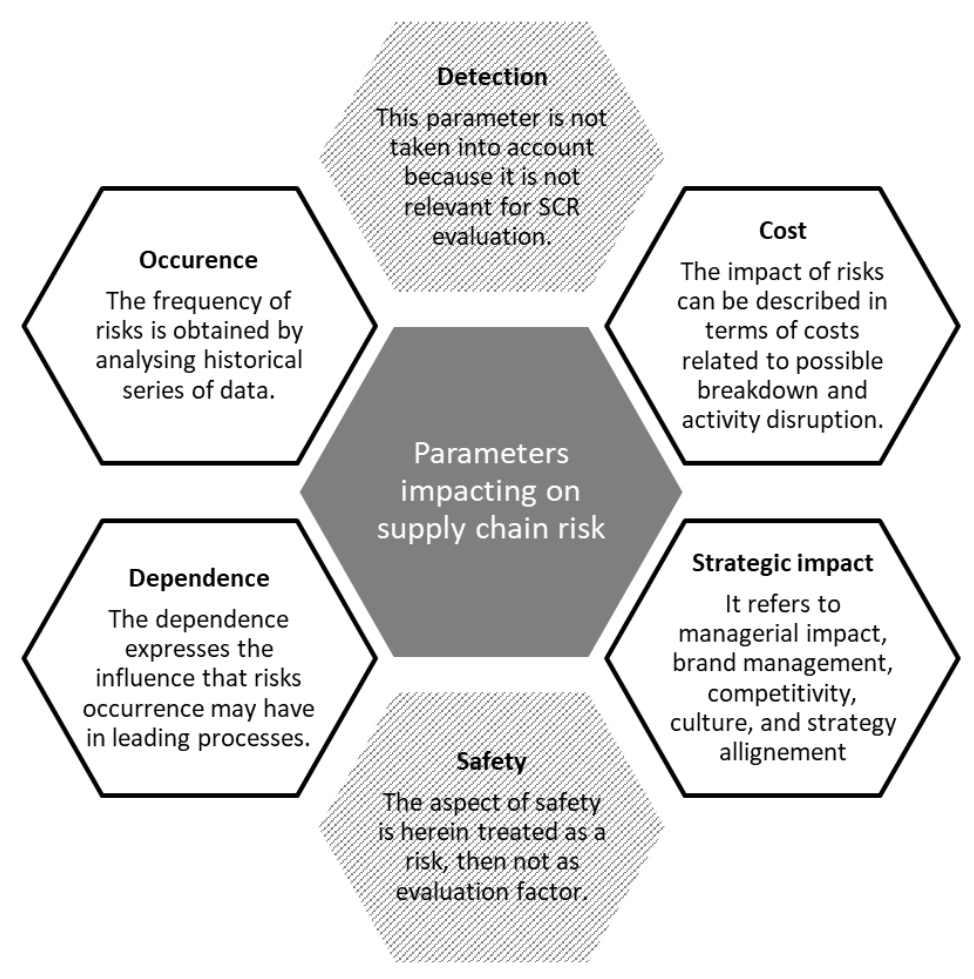

Figure 1. Analysis of the parameters impacting on SCRs.

As stated before, we propose to calculate a modified $R P N\left(R P N_{\text {new }}\right)$ aimed at eventually ranking SCRs according to four main criteria: occurrence $\left(C_{1}\right)$, dependence $\left(C_{2}\right)$, cost $\left(C_{3}\right)$ and strategic impact $\left(\mathrm{C}_{4}\right)$. The calculation needs evaluation of the criteria provided by experts, using, for example, the five-point scale $(1,5)$, as described next.

Occurrence represents the frequency of failure related to the probability of occurrence $P_{i}$, evaluated as detailed in Table 3, and its meaning remains invariant with respect to the traditional RPN calculation, as suggested by the standards of reference [12]. 
Table 3. Evaluation scale for the factor of occurrence.

\begin{tabular}{llcc}
\hline \multicolumn{1}{c}{ Evaluation } & \multicolumn{1}{c}{ Meaning } & Value & \multicolumn{1}{c}{$\boldsymbol{P}_{\boldsymbol{i}}$} \\
\hline Very high (VH) & Highly probable occurrences & 5 & $P_{i} \geq 0.2$ \\
High (H) & Repeated occurrences & 4 & $0.1 \leq P_{i}<0.2$ \\
Medium (M) & Occasional occurrences & 3 & $0.01 \leq P_{i}<0.1$ \\
Low (L) & Relatively few occurrences & 2 & $0.001 \leq P_{i}<0.01$ \\
Very low (VL) & The probability of occurrence is almost null & 1 & $0 \leq P_{i}<0.001$ \\
\hline
\end{tabular}

The traditional factor of severity is herein treated by means of two factors, which are more representative for SCs, namely, dependence $C_{2}$ and $\operatorname{cost} C_{3}$. They both represent how strongly a potential risk may impact on the global level of supply chain performance. We believe that the factor of dependence is an expression of severity of each risk, because a risk with an associated high value of prominence may have a more powerful influence on all the other aspects, and then on the occurrence of other risks. Moreover, the role played by this factor within the context of the supply chain is recognized as very important in the literature [28]. In addition, a risk with an associated high cost of intervention certainly has to be considered as more severe. Summing up, on the one hand, the higher the degree of dependence is associated with a risk, the more that same risk is significant and impacting in terms of criticality; on the other hand, the higher the cost is associated with a given risk, the more severe the same risk will be.

With relation to the parameter of dependence, we specify that it can be easily evaluated, also in conditions of low transparency, by treating the opinions given from a panel of experts, whose degree of uncertainty can be taken under control by translating them into fuzzy numbers. We will describe later the evaluation process of $C_{2}$ through the fuzzy DEMATEL procedure. The scale given in Table 4 was used to evaluate the factor of cost, $C_{3}$. According to the experts of the decision-making team we involved, the quantitative thresholds indicated in the following tables refer to the penalty that companies would have to pay per week if the supply was stopped. To note, $2 \mathrm{M} \$$ refers to the worst scenario ever, which is the total consumption of the security stock.

Table 4. Evaluation scale for the factor of cost.

\begin{tabular}{cccc}
\hline Evaluation & Meaning & Value & Shutdown Duration \\
\hline Very high $(\mathrm{VH})$ & $\begin{array}{c}\text { Total impact on production, cost higher than 2 M\$ if } \\
\text { the risk occurred }\end{array}$ & 5 & $>6$ working days \\
\hline High $(\mathrm{H})$ & $\begin{array}{c}\text { High impact on production, cost between 2 M\$ and } \\
500 \mathrm{~K} \text { if the risk occurred }\end{array}$ & 4 & $1.5-6$ working days \\
\hline Medium (M) & $\begin{array}{c}\text { Partial impact on production, cost between } 500 \mathrm{~K} \$ \\
\text { and 150 K\$ if the risk occurred }\end{array}$ & 3 & $0.5-1.5$ working days \\
\hline Low (L) & $\begin{array}{c}\text { Minor impact on production, cost between } 150 \mathrm{~K} \$ \\
\text { and 50 K\$ if the risk occurred }\end{array}$ & 2 & $2-12 \mathrm{~h}$ \\
\hline Very low $(\mathrm{VL})$ & $\begin{array}{c}\text { Insignificant impact on production, cost lower than } \\
50 \mathrm{~K} \text { if the risk occurred }\end{array}$ & 1 & $<2 \mathrm{~h}$ \\
\hline
\end{tabular}

Lastly, $\mathrm{C}_{4}$, strategic impact, offers a measure of the impact of each risk in terms of such fundamental aspects as decision and strategy management, competitiveness, reputation and brand management. Considering its primary importance for the SC field, this factor can be evaluated as shown in Table 5, similar to the suggestion by Debo et al. [61].

To complete this section, we present the proposal for the calculation of a new RPN that uses the above evaluations. 
Table 5. Evaluation scale for the factor strategic impact.

\begin{tabular}{ccc}
\hline Evaluation & Meaning & Value \\
\hline Very high $(\mathrm{VH})$ & Strong direct impact on company activity requiring an immediate change of the \\
adopted supply chain strategy & 5 \\
High $(\mathrm{H})$ & $\begin{array}{c}\text { Direct impact on company activity requiring a mitigation action to change the } \\
\text { adopted supply chain strategy }\end{array}$ & 4 \\
Medium $(\mathrm{M})$ & Indirect impact on company activity requiring few changes to the adopted & 3 \\
Low $(\mathrm{L})$ & Limply chain strategy & adopted supply chain strategy \\
Very low $(\mathrm{VL})$ & Insignificant indirect impact on company activity & 2 \\
\hline
\end{tabular}

Various studies have proposed the use of additional factors for ranking failures identified by FMEA applications [62]. For example, Bevilacqua et al. [60] propose six different factors and a new equation for the RPN calculation. We have adapted their equation in the following way:

$$
R P N_{\text {new, }} \quad i=\sum_{k=1}^{n} w_{k} \cdot \frac{g_{i k}}{\max _{k} g_{i k}}
$$

where $w_{k}$ is the weight of criterion $C_{k}$, and $g_{i k}$ the evaluation of risk $i$ under criterion $C_{k}$ normalized with respect to the maximum value evaluated for all the other risks under that criterion.

For our approach, $n=4$, since we consider four factors. Furthermore, as mentioned above, we suggest modifying the traditional calculation of the RPN by using weights $w_{k}$ to ponder the effect of these factors; these weights will be calculated by means of the AHP technique, concisely described in the following subsection.

\subsection{The AHP to Establish Weights for Factors}

The AHP is a helpful tool to drive subjective judgment towards effective solutions for decision-making problems, since it provides weights expressing the mutual importance of the elements considered in the analysis. The method is based on the construction of a hierarchical structure for representing the goal, criteria and alternatives of the analyzed decision-making problem through various levels.

Elements belonging to the same level of the structure are pairwise compared in relation to the elements belonging to the upper level, by collecting expert judgment. Judgments are expressed and numerically translated according to the nine-point linguistic scale proposed by Saaty [63] to fill in so-called pairwise comparison matrices (PCMs). The purpose is to calculate a vector of weights reflecting the grade of importance of a specific element with respect to the others.

In AHP, judgment consistency is crucial, and a certain degree of inconsistency is allowed when elucidating judgment, since human reasoning cannot be fully consistent. Consistency is evaluated through the consistency ratio [63]

$$
C R=\frac{C I}{R I}
$$

where $C I$ is the consistency index,

$$
C I=\frac{\lambda_{\max }-1}{n-1}
$$

and $\lambda_{\max }$ and $n$ being, respectively, the maximum (Perron) eigenvalue and the size of the matrix, and $R I$ the random index [56].

\subsection{Fuzzy DEMATEL to Evaluate the Factor of Dependence for Each Risk}

The DEMATEL technique in its crisp version makes use of expert opinions as input data expressed through crisp numbers to build relationships of dependence between each pair of elements characterizing the analysis. Since we are dealing with linguistic evaluations provided by decision makers, the fuzzy version of the method helps better manage the uncertainty affecting the input data. 
The first step to apply the methodology consists of determining the boundaries of the problem of interest and carefully defining the set of elements or objects of the analysis. Then, it will be important to accurately select the team of decision makers, on the basis of their professional backgrounds, skills and knowledge about the field under study.

Each decision maker will be asked to fill in a non-negative matrix $X$, showing linguistic evaluations of influence for each couple of elements according to the scale presented in Table 6 (similar to the one used by Mahmoudi et al. [64]). Each evaluation of influence corresponds to a triangular fuzzy number (TFN) $\widetilde{x}_{i j}=\left(a_{i j}, b_{i j}, c_{i j}\right)$, where $a_{i j} \leq b_{i j} \leq c_{i j}$. We specify that the input matrices are not symmetric, since elements may influence each other in a different way. Moreover, the main diagonals of those input matrices will be filled with evaluations corresponding to "NO", because an element is assumed as having no influence on itself.

Table 6. Linguistic scale and corresponding triangular fuzzy numbers (TFNs).

\begin{tabular}{cc}
\hline Linguistic Evaluation & TFN \\
\hline No influence (NO) & $(0.00,0.00,0.25)$ \\
Very low influence (VLI) & $(0.00,0.25,0.50)$ \\
Low Influence (LI) & $(0.25,0.50,0.75)$ \\
High Influence (HI) & $(0.50,0.75,1.00)$ \\
Very high influence (VI) & $(0.75,1.00,1.00)$ \\
\hline
\end{tabular}

Once collected, all the input matrices (one for each expert) will be first defuzzified into crisp input matrices by means of, for example, the graded mean integration approach (Equation (4)) and then aggregated into a single matrix, called direct relation matrix $D=(d)_{i j}$.

$$
x_{i j}=\frac{a_{i j}+4 b_{i j}+c_{i j}}{6} .
$$

At this stage, the direct relation matrix $D$ is normalized through multiplication:

$$
N=s D,
$$

using a coefficient $s$, a real number, slightly smaller than

$$
\min \left[\frac{1}{\max _{1 \leq i \leq n} \sum_{j=1}^{n} d_{i j}}, \frac{1}{\max _{1 \leq j \leq n} \sum_{i=1}^{n} d_{i j}}\right] .
$$

The procedure continues by accumulating all the indirect relations through the sum of the powers of the normalized direct relation matrix $N$ to get the total relation matrix $T$,

$$
T=N(I-N)^{-1}
$$

where $I$ is the identity matrix. That power series converge because of Equations (5) and (6), in that the spectral radius of $N$ is smaller than one (see, for example, [65]).

The next stage consists of calculating the vectors "prominence", $R+C$, and "relation", $R-C$, where $R$ and $C$ are, respectively, the sum of the rows, $r_{i}$, and the sum of the columns, $c$, of the total relation matrix $T$ :

$$
\begin{aligned}
& R=\sum_{i=1}^{n} r_{i}, \\
& C=\sum_{j=1}^{n} c_{j} .
\end{aligned}
$$

The prominence gives the overall effect that each element has on all the other ones and the relation helps categorize elements into groups of cause (if relation is higher than zero) or effect (if relation is lower than zero). 
The output of the procedure is a chart built by mapping prominence against relation, thus showing the interdependences among the elements. The two elements are linked in the chart by arrows just if the entry of $T$ corresponding to that pair is higher than a threshold calculated by averaging all the elements of the matrix [66]. This representation avoids considering the negligible effects of interdependence. Lastly, the elements can be ordered decreasingly according to their values of prominence. The elements occupying the first position of the ranking will be the ones characterized by a higher degree of interdependence with respect to all the others.

\section{Case Study}

This case study carries on the numerical evaluation of the SCRs given in Table 2, regarding the parameters highlighted in the previous section. To this effect, we calculated the modified RPN and got the final ranking of risks, the fundamental step to plan the implementation of suitable strategies of intervention. By leading various surveys within a team of experts with complementary professional backgrounds, we developed the following main steps:

1. Calculation of the vector of factor weights through the AHP technique.

2. Collection of evaluations related to those factors:

a. for factors $C_{1}, C_{3}$ and $C_{4}$, the experts give specific opinions producing numbers in the five-point scales, as seen in Tables $3-5$, respectively;

b. corresponding to the evaluation of $\mathrm{C}_{2}$, we use fuzzy DEMATEL, asking suitable experts to elicit fuzzy input matrices to get the prominence associated to the risks, which is discretized using a five-point scale.

3. Calculation of the values of the modified RPN by means of Equation (1), and formalization of the final ranking by ordering them in a decreasing way.

Regarding the application of the AHP to weight the factors, an expert on SCR performed a pairwise comparison using the Saaty scale. The corresponding PCM and the vector of weights are given in Table 7, which also shows an acceptable value of CR.

Table 7. Linguistic scale and corresponding TFNs.

\begin{tabular}{ccccccc}
\hline & $\mathrm{C}_{1}$ & $\mathrm{C}_{2}$ & $\mathrm{C}_{3}$ & $\mathrm{C}_{4}$ & Weights & CR \\
\cline { 1 - 5 } $\mathrm{C}_{\mathbf{1}}$ & 1 & $1 / 5$ & $1 / 5$ & $1 / 3$ & $6.79 \%$ & \\
\cline { 1 - 5 } $\mathrm{C}_{\mathbf{2}}$ & 5 & 1 & 1 & 3 & $38.99 \%$ & \multirow{2}{*}{0.0163} \\
\cline { 1 - 5 } $\mathrm{C}_{3}$ & 5 & 1 & 1 & 3 & $38.99 \%$ & \\
\cline { 1 - 5 } $\mathrm{C}_{4}$ & 3 & $1 / 3$ & $1 / 3$ & 1 & $15.23 \%$ & \\
\hline
\end{tabular}

For the second stage, evaluations were asked regarding $C_{1}, C_{3}$ and $C_{4}$, according to Tables $3-5$, respectively. These direct evaluations are presented later when summarizing the final results. In the case of $C_{2}$, to apply the fuzzy DEMATEL, we start by collecting three fuzzy input matrices by involving a decision-making group made of three experts: the first having practical expertise on safety and security in the automotive industry field, the second being the responsible of the quality and logistics department of a real company, and the third coming from the academic world, with expertise in supply chain management and logistics.

For the sake of conciseness, just one input matrix with linguistic evaluation is herein reported (Table 8) to show how the process of input data collection was led.

Tables 9 and 10 give the aggregated (crisp) direct relation matrix $D$, and the total relation matrix $T$, whereas the chart output of the procedure is shown in Figure 2. The arrows in the graph represent the correlation between two elements, existing when the corresponding entry of the total relation matrix of Table 10 exceeds 0.0345 , which is the average of all the elements of the same matrix. 
Table 8. Input matrix filled in by the expert on safety and security for the automotive industry.

\begin{tabular}{|c|c|c|c|c|c|c|c|c|c|c|c|c|c|c|c|c|c|c|c|c|c|c|c|}
\hline & $\mathbf{R}_{\mathbf{1}}$ & $\mathbf{R}_{2}$ & $\mathbf{R}_{\mathbf{3}}$ & $\mathbf{R}_{4}$ & $\mathbf{R}_{5}$ & $\mathbf{R}_{6}$ & $\mathbf{R}_{7}$ & $\mathbf{R}_{8}$ & $\mathbf{R}_{\mathbf{9}}$ & $\mathbf{R}_{10}$ & $\mathbf{R}_{11}$ & $\mathbf{R}_{12}$ & $\mathbf{R}_{13}$ & $\mathbf{R}_{14}$ & $\mathbf{R}_{15}$ & $\mathbf{R}_{16}$ & $\mathbf{R}_{17}$ & $\mathbf{R}_{\mathbf{1 8}}$ & $\mathbf{R}_{19}$ & $\mathbf{R}_{20}$ & $\mathbf{R}_{21}$ & $\mathbf{R}_{22}$ & $\mathbf{R}_{23}$ \\
\hline $\mathbf{R}_{1}$ & $\mathrm{NO}$ & $\mathrm{NO}$ & $\mathrm{NO}$ & $\mathrm{HI}$ & $\mathrm{NO}$ & $\mathrm{NO}$ & $\mathrm{NO}$ & VI & $\mathrm{NO}$ & VI & $\mathrm{NO}$ & VLI & $\mathrm{NO}$ & $\mathrm{NO}$ & $\mathrm{NO}$ & $\mathrm{NO}$ & VI & $\mathrm{NO}$ & LI & $\mathrm{HI}$ & $\mathrm{NO}$ & $\mathrm{NO}$ & $\mathrm{NO}$ \\
\hline $\mathbf{R}_{2}$ & $\mathrm{HI}$ & $\mathrm{NO}$ & $\mathrm{NO}$ & VLI & $\mathrm{NO}$ & $\mathrm{NO}$ & $\mathrm{NO}$ & HI & $\mathrm{NO}$ & VI & HI & VLI & $\mathrm{NO}$ & LI & $\mathrm{NO}$ & $\mathrm{NO}$ & VI & $\mathrm{HI}$ & VI & $\mathrm{HI}$ & NO & NO & NO \\
\hline $\mathbf{R}_{3}$ & LI & VI & $\mathrm{NO}$ & $\mathrm{HI}$ & HI & VLI & $\mathrm{NO}$ & $\mathrm{HI}$ & LI & $\mathrm{HI}$ & $\mathrm{HI}$ & $\mathrm{HI}$ & VLI & VI & $\mathrm{NO}$ & $\mathrm{NO}$ & $\mathrm{HI}$ & $\mathrm{HI}$ & $\mathrm{HI}$ & $\mathrm{HI}$ & $\mathrm{NO}$ & $\mathrm{NO}$ & $\mathrm{NO}$ \\
\hline $\mathbf{R}_{4}$ & $\mathrm{NO}$ & $\mathrm{NO}$ & HI & $\mathrm{NO}$ & LI & LI & $\mathrm{NO}$ & HI & LI & $\mathrm{HI}$ & LI & HI & VLI & $\mathrm{NO}$ & LI & $\mathrm{NO}$ & LI & LI & HI & HI & $\mathrm{NO}$ & $\mathrm{NO}$ & $\mathrm{NO}$ \\
\hline $\mathbf{R}_{5}$ & $\mathrm{HI}$ & $\mathrm{NO}$ & $\mathrm{NO}$ & VI & $\mathrm{NO}$ & VI & $\mathrm{NO}$ & VI & $\mathrm{NO}$ & VI & $\mathrm{NO}$ & VLI & $\mathrm{NO}$ & HI & $\mathrm{NO}$ & $\mathrm{NO}$ & LI & LI & VLI & VI & $\mathrm{NO}$ & $\mathrm{NO}$ & $\mathrm{HI}$ \\
\hline $\mathbf{R}_{6}$ & LI & $\mathrm{NO}$ & VLI & HI & VI & $\mathrm{NO}$ & $\mathrm{NO}$ & HI & $\mathrm{NO}$ & HI & $\mathrm{NO}$ & VLI & $\mathrm{NO}$ & VI & $\mathrm{NO}$ & $\mathrm{NO}$ & LI & LI & VLI & VI & $\mathrm{NO}$ & $\mathrm{NO}$ & $\mathrm{HI}$ \\
\hline $\mathbf{R}_{7}$ & $\mathrm{NO}$ & $\mathrm{NO}$ & $\mathrm{NO}$ & VI & LI & LI & $\mathrm{NO}$ & $\mathrm{HI}$ & $\mathrm{NO}$ & $\mathrm{NO}$ & VLI & $\mathrm{NO}$ & $\mathrm{NO}$ & VLI & $\mathrm{NO}$ & $\mathrm{NO}$ & $\mathrm{NO}$ & VLI & VLI & VLI & $\mathrm{NO}$ & VLI & VI \\
\hline $\mathbf{R}_{8}$ & $\mathrm{NO}$ & $\mathrm{NO}$ & $\mathrm{NO}$ & VI & $\mathrm{NO}$ & LI & $\mathrm{NO}$ & $\mathrm{NO}$ & $\mathrm{NO}$ & LI & $\mathrm{NO}$ & $\mathrm{NO}$ & $\mathrm{NO}$ & VLI & $\mathrm{NO}$ & $\mathrm{NO}$ & VLI & VLI & VLI & VLI & $\mathrm{NO}$ & $\mathrm{NO}$ & $\mathrm{NO}$ \\
\hline $\mathbf{R}_{\mathbf{9}}$ & $\mathrm{NO}$ & $\mathrm{NO}$ & $\mathrm{NO}$ & VI & VI & $\mathrm{NO}$ & $\mathrm{NO}$ & $\mathrm{NO}$ & $\mathrm{NO}$ & VI & $\mathrm{NO}$ & VI & VI & VLI & VI & VLI & LI & VI & VLI & VI & NO & NO & NO \\
\hline $\mathbf{R}_{10}$ & $\mathrm{NO}$ & $\mathrm{NO}$ & $\mathrm{NO}$ & VI & LI & $\mathrm{NO}$ & $\mathrm{NO}$ & $\mathrm{NO}$ & LI & $\mathrm{NO}$ & $\mathrm{NO}$ & $\mathrm{Vl}$ & VI & VLI & $\mathrm{NO}$ & LI & HI & VI & VLI & VI & $\mathrm{NO}$ & $\mathrm{NO}$ & $\mathrm{NO}$ \\
\hline $\mathbf{R}_{11}$ & $\mathrm{NO}$ & $\mathrm{NO}$ & $\mathrm{NO}$ & VI & VI & $\mathrm{NO}$ & $\mathrm{NO}$ & $\mathrm{NO}$ & $\mathrm{HI}$ & VI & $\mathrm{NO}$ & VI & VI & VLI & $\mathrm{HI}$ & $\mathrm{NO}$ & VLI & VI & VLI & VI & $\mathrm{NO}$ & $\mathrm{NO}$ & $\mathrm{NO}$ \\
\hline $\mathbf{R}_{12}$ & $\mathrm{NO}$ & $\mathrm{NO}$ & $\mathrm{NO}$ & VI & LI & $\mathrm{NO}$ & $\mathrm{NO}$ & $\mathrm{NO}$ & LI & VI & $\mathrm{NO}$ & $\mathrm{NO}$ & $\mathrm{NO}$ & VLI & VI & $\mathrm{NO}$ & $\mathrm{NO}$ & V & VLI & VI & $\mathrm{NO}$ & $\mathrm{NO}$ & $\mathrm{NO}$ \\
\hline $\mathbf{R}_{13}$ & $\mathrm{NO}$ & $\mathrm{NO}$ & $\mathrm{NO}$ & $\mathrm{NO}$ & LI & $\mathrm{NO}$ & $\mathrm{NO}$ & $\mathrm{NO}$ & $\mathrm{NO}$ & $\mathrm{NO}$ & $\mathrm{NO}$ & $\mathrm{HI}$ & $\mathrm{NO}$ & VLI & LI & $\mathrm{NO}$ & $\mathrm{NO}$ & LI & VLI & VLI & $\mathrm{NO}$ & $\mathrm{NO}$ & $\mathrm{HI}$ \\
\hline $\mathbf{R}_{14}$ & $\mathrm{NO}$ & $\mathrm{NO}$ & $\mathrm{NO}$ & VI & VI & $\mathrm{NO}$ & $\mathrm{NO}$ & $\mathrm{NO}$ & VI & VI & $\mathrm{NO}$ & $\mathrm{HI}$ & HI & $\mathrm{NO}$ & $\mathrm{NO}$ & $\mathrm{NO}$ & LI & VI & VLI & VI & NO & $\mathrm{NO}$ & NO \\
\hline $\mathbf{R}_{15}$ & $\mathrm{NO}$ & $\mathrm{NO}$ & $\mathrm{NO}$ & VI & VI & LI & $\mathrm{NO}$ & $\mathrm{NO}$ & VI & VI & LI & $\mathrm{HI}$ & VLI & VLI & $\mathrm{NO}$ & $\mathrm{NO}$ & LI & VI & VLI & VI & $\mathrm{NO}$ & $\mathrm{NO}$ & $\mathrm{NO}$ \\
\hline $\mathbf{R}_{16}$ & VI & $\mathrm{NO}$ & VLI & LI & LI & LI & $\mathrm{NO}$ & HI & $\mathrm{HI}$ & VI & VLI & VI & HI & VLI & VLI & $\mathrm{NO}$ & $\mathrm{NO}$ & $\mathrm{NO}$ & $\mathrm{NO}$ & VI & $\mathrm{NO}$ & $\mathrm{NO}$ & VI \\
\hline $\mathbf{R}_{17}$ & $\mathrm{NO}$ & $\mathrm{NO}$ & LI & VI & VI & HI & HI & VI & VI & VI & $\mathrm{HI}$ & VI & VI & $\mathrm{NO}$ & VI & VI & $\mathrm{NO}$ & NO & HI & VI & VLI & VLI & NO \\
\hline $\mathbf{R}_{18}$ & $\mathrm{NO}$ & VI & VLI & $\mathrm{HI}$ & LI & $\mathrm{NO}$ & $\mathrm{NO}$ & $\mathrm{NO}$ & $\mathrm{NO}$ & VI & VLI & VI & VI & $\mathrm{NO}$ & VI & LI & $\mathrm{HI}$ & $\mathrm{NO}$ & $\mathrm{NO}$ & VI & $\mathrm{NO}$ & $\mathrm{NO}$ & $\mathrm{NO}$ \\
\hline $\mathbf{R}_{19}$ & $\mathrm{NO}$ & $\mathrm{NO}$ & $\mathrm{NO}$ & LI & LI & $\mathrm{NO}$ & $\mathrm{NO}$ & VI & $\mathrm{NO}$ & VI & $\mathrm{NO}$ & VI & VI & $\mathrm{NO}$ & VLI & VLI & VI & $\mathrm{NO}$ & $\mathrm{NO}$ & $\mathrm{NO}$ & $\mathrm{NO}$ & $\mathrm{NO}$ & $\mathrm{NO}$ \\
\hline $\mathbf{R}_{20}$ & VI & $\mathrm{NO}$ & $\mathrm{NO}$ & VI & VI & HI & $\mathrm{NO}$ & V & $\mathrm{NO}$ & $\mathrm{NO}$ & $\mathrm{NO}$ & $\mathrm{HI}$ & VLI & $\mathrm{NO}$ & $\mathrm{HI}$ & $\mathrm{NO}$ & LI & VI & $\mathrm{HI}$ & $\mathrm{NO}$ & $\mathrm{NO}$ & LI & $\mathrm{NO}$ \\
\hline $\mathbf{R}_{21}$ & VI & $\mathrm{NO}$ & LI & VI & VI & HI & $\mathrm{NO}$ & VI & $\mathrm{NO}$ & $\mathrm{NO}$ & $\mathrm{NO}$ & HI & VLI & $\mathrm{NO}$ & HI & $\mathrm{NO}$ & LI & VI & $\mathrm{HI}$ & VI & NO & NO & NO \\
\hline $\mathbf{R}_{22}$ & VI & $\mathrm{NO}$ & LI & VI & VI & HI & HI & VI & $\mathrm{NO}$ & $\mathrm{NO}$ & VI & HI & VLI & $\mathrm{NO}$ & $\mathrm{HI}$ & $\mathrm{NO}$ & LI & VI & $\mathrm{HI}$ & VI & $\mathrm{NO}$ & NO & $\mathrm{NO}$ \\
\hline $\mathbf{R}_{23}$ & $\mathrm{NO}$ & $\mathrm{NO}$ & LI & $\mathrm{HI}$ & VI & VLI & $\mathrm{NO}$ & VLI & $\mathrm{NO}$ & $\mathrm{NO}$ & VLI & HI & $\mathrm{HI}$ & VI & $\mathrm{HI}$ & $\mathrm{NO}$ & HI & NO & $\mathrm{NO}$ & LI & NO & NO & NO \\
\hline
\end{tabular}


Table 9. Direct relation matrix $D$.

\begin{tabular}{|c|c|c|c|c|c|c|c|c|c|c|c|c|c|c|c|c|c|c|c|c|c|c|c|}
\hline & $\mathbf{R}_{1}$ & $\mathbf{R}_{2}$ & $\mathbf{R}_{3}$ & $\mathbf{R}_{\mathbf{4}}$ & $\mathbf{R}_{5}$ & $\mathbf{R}_{6}$ & $\mathbf{R}_{7}$ & $\mathbf{R}_{8}$ & $\mathbf{R}_{\mathbf{9}}$ & $\mathbf{R}_{10}$ & $\mathbf{R}_{11}$ & $\mathbf{R}_{12}$ & $\mathbf{R}_{13}$ & $\mathbf{R}_{14}$ & $\mathbf{R}_{15}$ & $\mathbf{R}_{16}$ & $\mathbf{R}_{17}$ & $\mathbf{R}_{\mathbf{1 8}}$ & $\mathbf{R}_{19}$ & $\mathbf{R}_{20}$ & $\mathbf{R}_{21}$ & $\mathbf{R}_{22}$ & $\mathbf{R}_{23}$ \\
\hline $\mathbf{R}_{1}$ & 0.04 & 0.04 & 0.04 & 0.82 & 0.04 & 0.04 & 0.04 & 0.82 & 0.04 & 0.89 & 0.04 & 0.33 & 0.04 & 0.04 & 0.11 & 0.04 & 0.96 & 0.04 & 0.58 & 0.82 & 0.04 & 0.04 & 0.11 \\
\hline $\mathbf{R}_{2}$ & 0.82 & 0.04 & 0.04 & 0.33 & 0.04 & 0.11 & 0.04 & 0.89 & 0.04 & 0.89 & 0.82 & 0.33 & 0.04 & 0.50 & 0.11 & 0.04 & 0.96 & 0.82 & 0.89 & 0.82 & 0.11 & 0.11 & 0.11 \\
\hline $\mathbf{R}_{3}$ & 0.50 & 0.74 & 0.04 & 0.75 & 0.89 & 0.18 & 0.04 & 0.82 & 0.81 & 0.82 & 0.75 & 0.82 & 0.42 & 0.96 & 0.04 & 0.04 & 0.75 & 0.75 & 0.82 & 0.82 & 0.11 & 0.04 & 0.04 \\
\hline $\mathbf{R}_{4}$ & 0.04 & 0.04 & 0.82 & 0.04 & 0.42 & 0.58 & 0.11 & 0.82 & 0.42 & 0.82 & 0.58 & 0.82 & 0.33 & 0.04 & 0.50 & 0.04 & 0.42 & 0.42 & 0.89 & 0.75 & 0.04 & 0.04 & 0.04 \\
\hline $\mathbf{R}_{5}$ & 0.89 & 0.04 & 0.04 & 0.89 & 0.04 & 0.89 & 0.11 & 0.82 & 0.04 & 0.89 & 0.11 & 0.33 & 0.11 & 0.75 & 0.04 & 0.04 & 0.42 & 0.42 & 0.42 & 0.89 & 0.11 & 0.04 & 0.82 \\
\hline $\mathbf{R}_{6}$ & 0.58 & 0.11 & 0.33 & 0.82 & 0.82 & 0.04 & 0.04 & 0.82 & 0.04 & 0.82 & 0.04 & 0.33 & 0.04 & 0.96 & 0.04 & 0.04 & 0.42 & 0.50 & 0.33 & 0.89 & 0.04 & 0.04 & 0.89 \\
\hline $\mathbf{R}_{7}$ & 0.04 & 0.04 & 0.04 & 0.89 & 0.42 & 0.58 & 0.04 & 0.82 & 0.04 & 0.04 & 0.25 & 0.04 & 0.04 & 0.33 & 0.04 & 0.04 & 0.04 & 0.33 & 0.42 & 0.25 & 0.04 & 0.42 & 0.89 \\
\hline $\mathbf{R}_{8}$ & 0.04 & 0.04 & 0.04 & 0.89 & 0.04 & 0.58 & 0.04 & 0.04 & 0.04 & 0.58 & 0.11 & 0.04 & 0.04 & 0.33 & 0.04 & 0.04 & 0.33 & 0.25 & 0.42 & 0.25 & 0.04 & 0.04 & 0.04 \\
\hline $\mathbf{R}_{\mathbf{9}}$ & 0.11 & 0.04 & 0.04 & 0.82 & 0.89 & 0.11 & 0.04 & 0.04 & 0.04 & 0.89 & 0.04 & 0.82 & 0.89 & 0.25 & 0.89 & 0.33 & 0.50 & 0.96 & 0.33 & 0.89 & 0.04 & 0.04 & 0.04 \\
\hline $\mathbf{R}_{10}$ & 0.11 & 0.04 & 0.04 & 0.89 & 0.58 & 0.11 & 0.04 & 0.04 & 0.58 & 0.04 & 0.04 & 0.89 & 0.96 & 0.33 & 0.04 & 0.42 & 0.75 & 0.89 & 0.42 & 0.89 & 0.04 & 0.04 & 0.04 \\
\hline $\mathbf{R}_{11}$ & 0.04 & 0.04 & 0.04 & 0.89 & 0.96 & 0.04 & 0.04 & 0.04 & 0.89 & 0.89 & 0.04 & 0.89 & 0.89 & 0.25 & 0.82 & 0.04 & 0.25 & 0.89 & 0.33 & 0.89 & 0.04 & 0.04 & 0.04 \\
\hline $\mathbf{R}_{12}$ & 0.04 & 0.11 & 0.04 & 0.96 & 0.58 & 0.04 & 0.04 & 0.04 & 0.50 & 0.96 & 0.04 & 0.04 & 0.04 & 0.33 & 0.96 & 0.04 & 0.04 & 0.89 & 0.42 & 0.96 & 0.04 & 0.04 & 0.04 \\
\hline $\mathbf{R}_{13}$ & 0.11 & 0.04 & 0.04 & 0.04 & 0.58 & 0.11 & 0.04 & 0.11 & 0.04 & 0.04 & 0.04 & 0.82 & 0.04 & 0.25 & 0.42 & 0.04 & 0.04 & 0.50 & 0.42 & 0.33 & 0.04 & 0.04 & 0.89 \\
\hline $\mathbf{R}_{14}$ & 0.11 & 0.04 & 0.04 & 0.89 & 0.65 & 0.04 & 0.11 & 0.04 & 0.89 & 0.82 & 0.04 & 0.75 & 0.89 & 0.04 & 0.04 & 0.04 & 0.42 & 0.96 & 0.42 & 0.96 & 0.04 & 0.04 & 0.04 \\
\hline $\mathbf{R}_{15}$ & 0.11 & 0.04 & 0.04 & 0.96 & 0.96 & 0.42 & 0.04 & 0.04 & 0.89 & 0.89 & 0.58 & 0.82 & 0.42 & 0.25 & 0.04 & 0.04 & 0.42 & 0.96 & 0.33 & 0.89 & 0.04 & 0.04 & 0.04 \\
\hline $\mathbf{R}_{16}$ & 0.82 & 0.11 & 0.33 & 0.42 & 0.42 & 0.42 & 0.04 & 0.82 & 0.82 & 0.82 & 0.33 & 0.89 & 0.82 & 0.33 & 0.33 & 0.04 & 0.04 & 0.04 & 0.04 & 0.89 & 0.04 & 0.04 & 0.96 \\
\hline $\mathbf{R}_{17}$ & 0.04 & 0.04 & 0.58 & 0.96 & 0.89 & 0.82 & 0.82 & 0.89 & 0.89 & 0.89 & 0.75 & 0.96 & 0.89 & 0.04 & 0.96 & 0.96 & 0.04 & 0.04 & 0.89 & 0.89 & 0.33 & 0.42 & 0.04 \\
\hline $\mathbf{R}_{18}$ & 0.11 & 0.82 & 0.42 & 0.82 & 0.58 & 0.04 & 0.11 & 0.11 & 0.04 & 0.82 & 0.42 & 0.89 & 0.96 & 0.04 & 0.81 & 0.42 & 0.82 & 0.04 & 0.04 & 0.89 & 0.04 & 0.04 & 0.04 \\
\hline $\mathbf{R}_{19}$ & 0.04 & 0.04 & 0.04 & 0.50 & 0.58 & 0.04 & 0.11 & 0.96 & 0.04 & 0.82 & 0.04 & 0.96 & 0.89 & 0.04 & 0.42 & 0.33 & 0.89 & 0.04 & 0.04 & 0.04 & 0.04 & 0.04 & 0.04 \\
\hline $\mathbf{R}_{20}$ & 0.82 & 0.04 & 0.04 & 0.74 & 0.82 & 0.89 & & & & & & & & & & & 0.50 & & & 0.04 & & 0.42 & 0.04 \\
\hline $\mathbf{R}_{21}$ & 0.82 & 0.04 & 0.67 & 0.74 & 0.89 & 0.82 & 0.04 & 0.89 & 0.04 & 0.04 & 0.04 & 0.75 & 0.33 & 0.04 & 0.89 & 0.04 & 0.42 & 0.72 & 0.82 & 0.65 & 0.04 & 0.04 & 0.18 \\
\hline $\mathbf{R}_{22}$ & 0.82 & 0.04 & 0.50 & 0.74 & 0.82 & 0.89 & 0.82 & 0.96 & 0.11 & 0.18 & 0.89 & 0.75 & 0.25 & 0.04 & 0.89 & 0.04 & 0.50 & 0.81 & 0.82 & 0.65 & 0.04 & 0.04 & 0.04 \\
\hline $\mathbf{R}_{23}$ & 0.11 & 0.11 & 0.67 & 0.82 & 0.89 & 0.42 & 0.04 & 0.33 & 0.11 & 0.11 & 0.57 & 0.82 & 0.82 & 0.74 & 0.82 & 0.04 & 0.75 & 0.04 & 0.04 & 0.50 & 0.04 & 0.04 & 0.04 \\
\hline
\end{tabular}


Table 10. Total relation matrix $T$.

\begin{tabular}{|c|c|c|c|c|c|c|c|c|c|c|c|c|c|c|c|c|c|c|c|c|c|c|c|}
\hline & $\mathbf{R}_{\mathbf{1}}$ & $\mathbf{R}_{2}$ & $\mathbf{R}_{3}$ & $\mathbf{R}_{\mathbf{4}}$ & $\mathbf{R}_{5}$ & $\mathbf{R}_{6}$ & $\mathbf{R}_{7}$ & $\mathbf{R}_{8}$ & $\mathbf{R}_{\mathbf{9}}$ & $\mathbf{R}_{10}$ & $\mathbf{R}_{11}$ & $\mathbf{R}_{12}$ & $\mathbf{R}_{13}$ & $\mathbf{R}_{14}$ & $\mathbf{R}_{15}$ & $\mathbf{R}_{16}$ & $\mathbf{R}_{17}$ & $\mathbf{R}_{\mathbf{1 8}}$ & $\mathbf{R}_{19}$ & $\mathbf{R}_{20}$ & $\mathbf{R}_{21}$ & $\mathbf{R}_{22}$ & $\mathbf{R}_{23}$ \\
\hline $\mathbf{R}_{1}$ & 0.01 & 001 & 0.01 & 008 & 0,03 & 0,02 & 0.01 & 0.07 & ?00 & 808 & 001 & 005 & 0.02 & 0.01 & 003 & 0.01 & 18 & 3 & .06 & .08 & 0.01 & 0.01 & 0.01 \\
\hline $\mathbf{R}_{2}$ & 06 & 01 & 02 & & & & & & & & & & & & & & 0.09 & 0.08 & 0.09 & 0.09 & 0.01 & 0.01 & 0.02 \\
\hline $\mathbf{R}_{3}$ & 0.05 & 0.05 & 0.02 & 0.11 & 0.10 & 0.04 & 0.01 & 0.09 & 0.08 & 0.11 & 0.07 & 0.11 & 0.07 & 0.08 & 0.04 & 0.02 & 0.09 & 0.09 & 0.09 & 0.11 & 0.01 & 0.01 & 0.02 \\
\hline $\mathbf{R}_{4}$ & 0.02 & 0.01 & 0.06 & 0.05 & 0.07 & 0.06 & 0.01 & 0.08 & 0.05 & 0.09 & 0.05 & 0.09 & 0.05 & 0.02 & 0.06 & & 0.06 & 0.06 & 0.08 & 0.09 & 0.01 & 0.01 & 0.02 \\
\hline $\mathbf{R}_{5}$ & 7 & 1 & 0 & & & & & & & & & & & & & & 0.06 & 0.06 & 0.06 & 0.10 & 0.01 & & 0.06 \\
\hline $\mathbf{R}_{6}$ & 0.05 & & & & & & & & & & & & & & & & 6 & 6 & 5 & 0 & 1 & & 0.07 \\
\hline $\mathbf{R}_{7}$ & 0.01 & & & & & & & & & & & & 0.02 & & 0.02 & & .02 & .04 & & 0.04 & & & 0.06 \\
\hline $\mathbf{R}_{8}$ & 01 & & & & & & & & & & & & & & & & & & & 0.04 & & & 0.01 \\
\hline $\mathbf{R}_{9}$ & 03 & 1 & & & & & & & & & & & 0.08 & & 0.08 & & 0.06 & 0.09 & 0.05 & 0.10 & & & 0.02 \\
\hline $\mathbf{R}_{10}$ & 02 & 01 & 0 & & 0.07 & 0.03 & 0 & 0 & & 0. & 0. & 0 & 0.09 & 0.04 & 0.03 & 0.04 & 0.07 & 0.09 & 0.05 & 0.10 & 0.01 & 0.01 & 0.02 \\
\hline $\mathbf{R}_{11}$ & 0.02 & 0.01 & 0.0 & 0 & 0. & 0. & 0.0 & 0. & 0. & 0.10 & 0.02 & 0.10 & 0.09 & 0.03 & 0.08 & 0.01 & 0.05 & 0.09 & 0.05 & 0.10 & 0.01 & 0.01 & 0.02 \\
\hline $\mathbf{R}_{12}$ & 0.02 & 0.01 & 0.0 & 0 & 0.1 & 0. & 0. & 0. & 0. & 0. & 0. & 0. & 0.03 & 0. & 0. & & 0.03 & 0.09 & 0.05 & 0.10 & 0.01 & 0.01 & 0.01 \\
\hline $\mathrm{R}_{1}$ & 0 & & & & & & & & & & & & & & & & 0.02 & 0.05 & 0.04 & 0.05 & 0 & 0.01 & 0.06 \\
\hline $\mathbf{R}_{14}$ & 0.02 & 0 & 0.02 & 0 & 0.1 & 0.02 & 0.1 & 0. & 0. & 0. & 0.02 & 0. & 0.08 & 0.02 & 0.03 & 0 & 0.05 & 0.09 & 0.05 & 0.10 & 0.01 & 0.01 & 0.02 \\
\hline $\mathbf{R}_{15}$ & 0.03 & 0 & 0.02 & & & & & & & & 0.05 & 0.10 & 0.06 & 0.03 & 0.04 & 0.02 & 0.06 & 0.10 & 0.05 & 0.10 & 0.01 & 0.01 & 0.02 \\
\hline $\mathbf{R}_{16}$ & 0.07 & 0.01 & 0.03 & 0.08 & 0.07 & 0.05 & 0.01 & 0.08 & 0.07 & 0.09 & 0.04 & 0.10 & 0.08 & 0.04 & 0.05 & 0.01 & 0.04 & 0.04 & 0.04 & 0.10 & 0.01 & 0.01 & 0.07 \\
\hline $\mathbf{R}_{17}$ & 0.03 & 0.01 & 0.05 & 0.13 & 0.11 & 0.09 & 0.0 & 0.10 & 0.09 & 0.1 & 0.07 & 0.12 & 0.10 & 0.03 & 0.10 & 0.07 & 0.05 & 0.06 & 0.10 & 0.12 & 0.03 & 0.03 & 0.03 \\
\hline $\mathbf{R}_{18}$ & 0.03 & 0.06 & 0.04 & & & 0.03 & 0.02 & & & & & & 0. & 0.02 & 0.08 & 0.04 & 0.08 & 0.04 & 0.04 & 0.10 & 0.01 & 0.01 & 0.02 \\
\hline $\mathbf{R}_{19}$ & 0 & 0 & 0 & 0 & 0 & 0 & 0. & & & & & & & & & & 0.07 & 0.03 & 0.03 & 0.04 & 0.01 & 0.01 & 0.02 \\
\hline $\mathbf{R}_{20}$ & & & & & & & & & & & & & & & & & & & & & & & 0.02 \\
\hline $\mathbf{R}_{21}$ & 0.07 & 0.01 & 0.05 & 0.10 & 0.0 & 0.08 & 0.01 & 0.09 & 0.03 & 0.05 & 0.02 & 0.09 & 0.05 & 0.03 & 0.08 & 0.01 & 0.06 & 0.08 & 0.08 & 0.09 & 0.01 & 0.01 & 0.03 \\
\hline $\mathbf{R}_{22}$ & 0.07 & 0.01 & 0.05 & 0.11 & 0.10 & 0.08 & 0.06 & 0.10 & 0.03 & 0.07 & 0.07 & 0.10 & 0.05 & 0.03 & 0.09 & 0.02 & 0.07 & 0.09 & 0.09 & 0.10 & 0.01 & 0.01 & 0.02 \\
\hline $\mathbf{R}_{23}$ & 0.02 & 0.01 & 0.05 & 0.10 & 0.09 & 0.05 & 0.01 & 0.05 & 0.03 & 0.05 & 0.05 & 0.09 & 0.08 & 0.06 & 0.08 & 0.01 & 0.07 & 0.04 & 0.04 & 0.08 & 0.01 & 0.01 & 0.02 \\
\hline
\end{tabular}




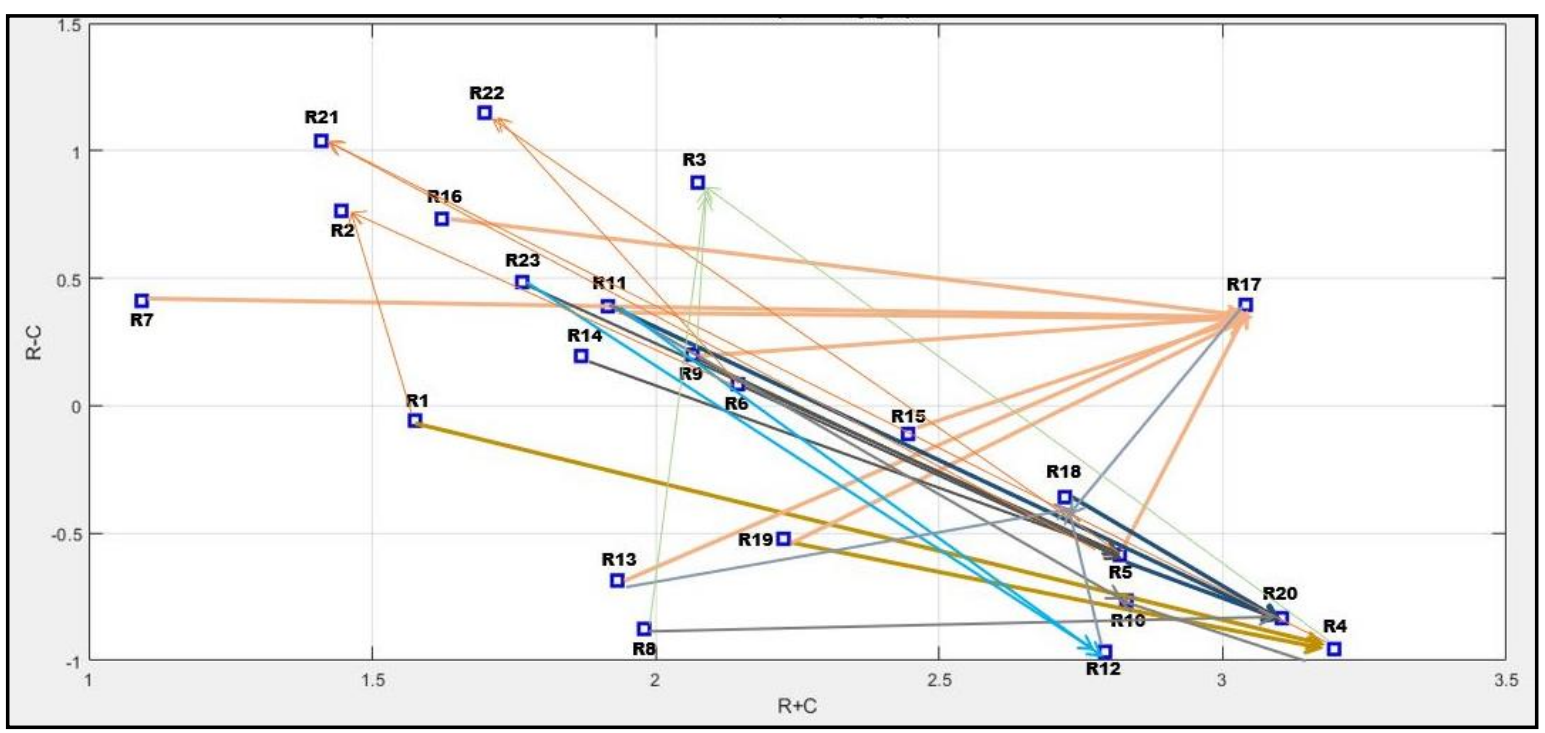

Figure 2. Risk interdependence graph.

Table 11 shows the values of prominence and relation for each risk, along with the corresponding evaluation using the five-point scale defined by the following prominence ranges: Attribute a score of

- 1 for values of prominence $R+C \leq 1.5$;

- 2 for $1.5<R+C \leq 2$;

- 3 for $2<R+C \leq 2.5$;

- $\quad 4$ for $2.5<R+C \leq 3$; and

- $\quad 5$ for $R+C>3$.

By analyzing the data in Table 11, one can observe that the risks with higher associated prominence are $R_{4}$ (requirement accomplishment), $R_{20}$ (supply chain disruptions due to natural disasters) and $R_{17}$ (manufacturing facilities, human resources, policies and processes breakdown). This result responds, first of all, to the supply chain constrain of having a completely flexible and cooperative supply because unexpected and permanent changes may occur. Indeed, the selection of a reliable supplier is a crucial factor to build a true partnership capable of supporting the company growth.

Table 12 finally summarizes all the results by also giving, for each supply chain risk, the evaluations for factors $C_{1}, C_{3}$ and $C_{4}$, the calculation of the new RPN by means of Equation (1), and the position occupied by each risk in the final ranking. Note that the evaluations for factors $C_{1}$, $C_{3}$ and $C_{4}$ (occurrence, cost and strategic impact) have been derived by involving another team of decision-makers, this time made up of five experts, namely, a manager engineer, warehouse manager, quality supervisor, supply chain engineer and supplier quality engineer. Each expert evaluated the factors according to the scales presented in Section 3.1, and then the average values of these evaluations was calculated.

As emerged from the new RPN calculation, the following aspects have been highlighted as priorities: $\mathrm{R}_{20}$ (supply chain disruptions due to natural disasters), $\mathrm{R}_{17}$ (manufacturing facilities, human resources, policies and processes breakdown) and $R_{5}$ (ineffective transport). The aspects that can be managed with less urgency are $R_{7}$ (taxes increase), $R_{2}$ (sudden design changes) and $R_{21}$ (supply chain disruptions due to events of terrorism). 
Table 11. Prominence and relation for each risk and evaluation scale of the dependence factor.

\begin{tabular}{|c|c|c|c|}
\hline SCR & $R+C$ & $R-C$ & Dependence Value \\
\hline $\mathbf{R}_{1}$ & 1.575906933 & -0.059574485 & 2 \\
\hline $\mathbf{R}_{2}$ & 1.446136645 & 0.766791476 & 1 \\
\hline $\mathbf{R}_{3}$ & 2.074929269 & 0.874509932 & 3 \\
\hline $\mathbf{R}_{4}$ & 3.195208982 & -0.953243888 & 5 \\
\hline $\mathbf{R}_{5}$ & 2.818098997 & -0.585297495 & 4 \\
\hline $\mathbf{R}_{6}$ & 2.14597612 & 0.081693943 & 3 \\
\hline $\mathbf{R}_{7}$ & 1.092209138 & 0.409585536 & 1 \\
\hline $\mathbf{R}_{8}$ & 1.978866896 & -0.874373105 & 2 \\
\hline $\mathbf{R}_{\mathbf{9}}$ & 2.06414083 & 0.198886518 & 3 \\
\hline $\mathbf{R}_{10}$ & 2.830483133 & -0.76334006 & 4 \\
\hline $\mathbf{R}_{11}$ & 1.915907794 & 0.389014775 & 2 \\
\hline $\mathbf{R}_{12}$ & 2.79132515 & -0.965713152 & 4 \\
\hline $\mathbf{R}_{13}$ & 1.932940838 & -0.684755427 & 2 \\
\hline $\mathbf{R}_{14}$ & 1.868252585 & 0.194208892 & 2 \\
\hline $\mathbf{R}_{15}$ & 2.444012115 & -0.109352862 & 3 \\
\hline $\mathbf{R}_{16}$ & 1.622819406 & 0.733138196 & 2 \\
\hline $\mathbf{R}_{17}$ & 3.04077581 & 0.392773267 & 5 \\
\hline $\mathbf{R}_{18}$ & 2.721618777 & -0.35972469 & 4 \\
\hline $\mathbf{R}_{19}$ & 2.224783501 & -0.5234403 & 3 \\
\hline $\mathbf{R}_{20}$ & 3.103872165 & -0.835962299 & 5 \\
\hline $\mathbf{R}_{21}$ & 1.410208574 & 1.040909665 & 1 \\
\hline $\mathbf{R}_{22}$ & 1.699433746 & 1.147979771 & 2 \\
\hline $\mathbf{R}_{23}$ & 1.764871856 & 0.485285791 & 2 \\
\hline
\end{tabular}

To test the robustness of our results, we have performed a sensitivity analysis by considering six scenarios of criteria weights. This kind of analysis is important to detect variations in the final ranking by varying the importance attributed to the considered factors. If present, these variations should be considered when planning interventions of risk management, in order to assure as much high-level security as possible. The scenarios are detailed as follows.

- $\quad 1$ st scenario, vector of weights: $(0.0679,0.4399,0.4399,0.0523)$. We keep the same importance for the occurrence factor, while varying both the dependence and the cost by +0.05 and the strategic impact by -0.10 .

- 2nd scenario, vector of weights: $(0.0679,0.3399,0.3399,0.2523)$. We also keep the same importance for occurrence, while varying both the dependence and the cost by -0.05 and the strategic impact by +0.10 .

- $\quad 3 r d$ scenario, vector of weights: $(0.0679,0.2899,0.2899,0.3523)$. We keep the same importance for occurrence, while varying both dependence and cost by -0.10 and the strategic impact by +0.20 .

- $\quad 4$ th scenario, vector of weights: $(0.1679,0.3399,0.3399,0.1523)$. We vary the occurrence of +0.10 , and also vary both the dependence and the cost of -0.05 , while keeping at the same importance the factor of strategic impact.

- 5 th scenario, vector of weights: $(0.2679,0.2899,0.2899,0.1523)$. We vary the occurrence factor by +0.20 , and dependence and cost by -0.10 , while keeping the at the same importance the strategic impact factor. 
- $\quad 6$ th scenario, vector of weights: $(0.30,0.20,0.20,0.30)$. We attribute more importance to occurrence and strategic impact (both weights equal to 30\%) and less to the factors representing severity (both weights equal to $20 \%$ ).

Table 12. New Risk Priority Number (RPN) calculation and final ranking.

\begin{tabular}{|c|c|c|c|c|c|c|}
\hline Weights SCR & $6.79 \%$ & $38.99 \%$ & $38.99 \%$ & $15.23 \%$ & $R P N_{n e w}$ & Ranking Position \\
\hline $\mathbf{R}_{1}$ & 4.6 & 2.00 & 4.2 & 3.8 & 0.7517 & 9 th \\
\hline $\mathbf{R}_{2}$ & 2.8 & 1.00 & 3.6 & 2.8 & 0.5549 & 21st \\
\hline $\mathbf{R}_{3}$ & 2.4 & 3.00 & 3 & 3.6 & 0.6777 & 14th \\
\hline $\mathbf{R}_{4}$ & 2.8 & 5.00 & 2.8 & 3.4 & 0.8140 & 5 th \\
\hline $\mathbf{R}_{7}$ & 2.6 & 1.00 & 3.4 & 4 & 0.5761 & 20th \\
\hline $\mathbf{R}_{8}$ & 3.2 & 2.00 & 3.8 & 3.2 & 0.6718 & 15th \\
\hline $\mathbf{R}_{\mathbf{9}}$ & 2 & 3.00 & 3.8 & 2.8 & 0.7173 & 10 th \\
\hline $\mathbf{R}_{\mathbf{1 0}}$ & 2.8 & 4.00 & 3.8 & 3 & 0.8146 & 4 th \\
\hline $\mathbf{R}_{11}$ & 2.4 & 2.00 & 3.6 & 3.6 & 0.6554 & 16th \\
\hline $\mathbf{R}_{16}$ & 3 & 2.00 & 3 & 3 & 0.5874 & 19th \\
\hline $\mathbf{R}_{17}$ & 2.4 & 5.00 & 3.2 & 3.8 & 0.8594 & $2 \mathrm{nd}$ \\
\hline $\mathbf{R}_{18}$ & 2.6 & 4.00 & 3.4 & 3.4 & 0.7887 & 6 th \\
\hline $\mathbf{R}_{19}$ & 3 & 3.00 & 4 & 3.8 & 0.7868 & 7 th \\
\hline $\mathbf{R}_{\mathbf{2 0}}$ & 2.2 & 5.00 & 4.2 & 3.6 & 0.9420 & $1 \mathrm{st}$ \\
\hline $\mathbf{R}_{21}$ & 1.6 & 1.00 & 3.2 & 4 & 0.5423 & $22 \mathrm{nd}$ \\
\hline $\mathbf{R}_{22}$ & 2 & 2.00 & 3.2 & 4.2 & 0.6336 & 17th \\
\hline $\mathbf{R}_{23}$ & 2.8 & 2.00 & 3.8 & 4.2 & 0.7517 & 9 th \\
\hline
\end{tabular}

The results of the sensitivity analysis in terms of the positions occupied by each SCR in the final RPN ranking for each scenario are shown in Table 13, and graphically synthetized in Figure 3.

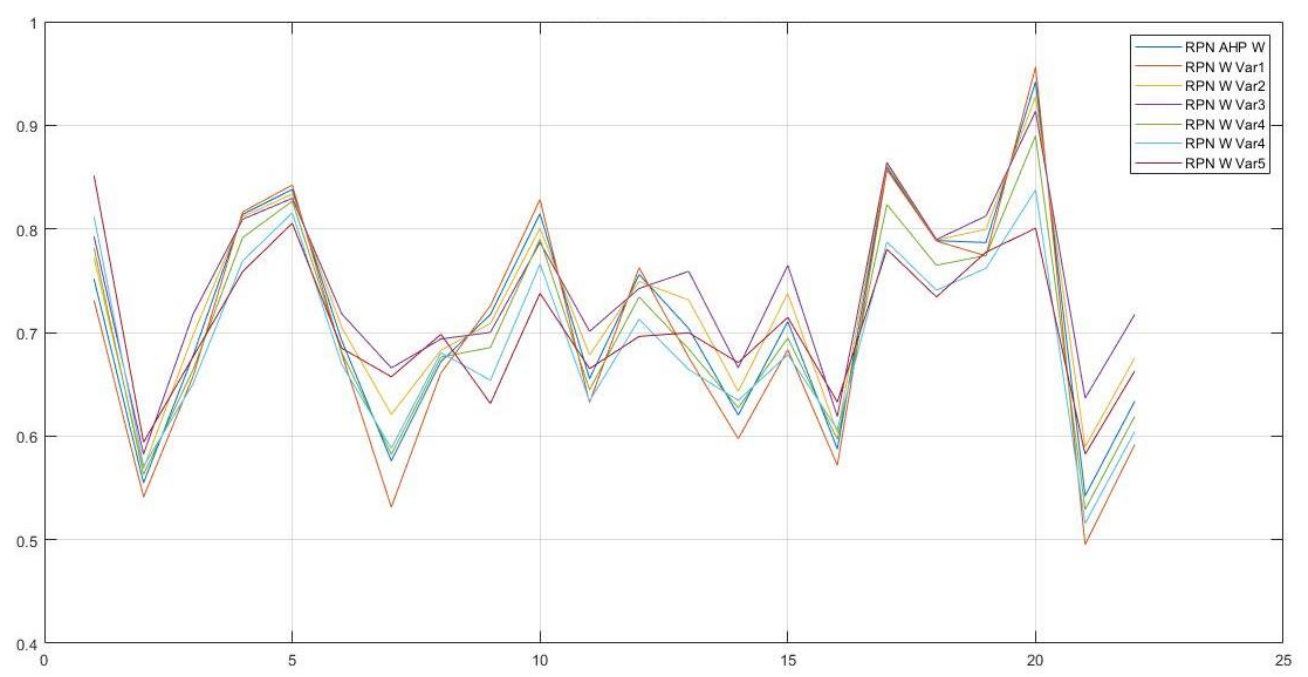

Figure 3. Sensitivity analysis for the RPN values in various scenarios regarding the factors' weights. 
Table 13. Sensitivity analysis varying the weights of factors.

\begin{tabular}{|c|c|c|c|c|c|c|}
\hline \multirow[b]{2}{*}{ SCR } & \multicolumn{6}{|c|}{ Ranking Position } \\
\hline & $\begin{array}{c}\text { 1st } \\
\text { SCENARIO }\end{array}$ & $\begin{array}{c}\text { 2nd } \\
\text { SCENARIO }\end{array}$ & $\begin{array}{c}\text { 3rd } \\
\text { SCENARIO }\end{array}$ & $\begin{array}{c}\text { 4th } \\
\text { SCENARIO }\end{array}$ & $\begin{array}{c}\text { 5th } \\
\text { SCENARIO }\end{array}$ & $\begin{array}{c}\text { 6th } \\
\text { SCENARIO }\end{array}$ \\
\hline $\mathbf{R}_{1}$ & 9th & 8th & 6th & 6th & $3 r d$ & 1 st \\
\hline $\mathbf{R}_{2}$ & 20th & 22nd & 22nd & $21 \mathrm{st}$ & $21 \mathrm{st}$ & $21 \mathrm{st}$ \\
\hline $\mathbf{R}_{3}$ & 15th & 14th & 13th & 15th & 15th & 14th \\
\hline $\mathbf{R}_{4}$ & 5 th & 4 th & 5 th & 4 th & 5 th & 6 th \\
\hline $\mathbf{R}_{5}$ & $3 \mathrm{rd}$ & $3 \mathrm{rd}$ & $3 \mathrm{rd}$ & 2nd & 2 nd & 2nd \\
\hline $\mathbf{R}_{6}$ & 12th & 13th & 12th & 13th & 12th & 13th \\
\hline $\mathbf{R}_{7}$ & $21 \mathrm{st}$ & 19th & 19th & 20th & 20th & 18th \\
\hline $\mathbf{R}_{8}$ & 14th & 15th & 17th & 14th & 10th & 11th \\
\hline $\mathbf{R}_{9}$ & 10th & 12 th & 16th & 11th & 14 th & 20th \\
\hline $\mathbf{R}_{10}$ & 4th & 5 th & 8 th & 5 th & 6th & 7 th \\
\hline $\mathbf{R}_{11}$ & 16th & 16th & 15th & 16th & 17 th & 16th \\
\hline $\mathbf{R}_{12}$ & 8 th & 9th & 11th & 9th & 9th & 12 th \\
\hline $\mathbf{R}_{13}$ & 13th & 11th & 10th & 12th & 13th & 10th \\
\hline $\mathbf{R}_{14}$ & 17 th & 18th & 18th & 17th & 16th & 15th \\
\hline $\mathbf{R}_{15}$ & 11th & 10th & 9 th & 10th & 11th & 9th \\
\hline $\mathbf{R}_{16}$ & 19th & 20th & $21 \mathrm{st}$ & 19th & 18th & 19th \\
\hline $\mathbf{R}_{17}$ & 2nd & 2nd & 2nd & $3 \mathrm{rd}$ & 4th & 4th \\
\hline $\mathbf{R}_{18}$ & 6th & 7th & 7th & 8th & 8th & 8th \\
\hline $\mathbf{R}_{19}$ & 7 th & 6th & 4 th & 7th & 7th & 5th \\
\hline $\mathbf{R}_{20}$ & $1 \mathrm{st}$ & $1 \mathrm{st}$ & $1 \mathrm{st}$ & $1 \mathrm{st}$ & $1 \mathrm{st}$ & $3 \mathrm{rd}$ \\
\hline $\mathbf{R}_{21}$ & $22 \mathrm{nd}$ & $21 \mathrm{st}$ & 20th & 22nd & $22 \mathrm{nd}$ & $22 \mathrm{nd}$ \\
\hline $\mathbf{R}_{22}$ & 18th & 17th & 14th & 18th & 19th & 17th \\
\hline $\mathbf{R}_{23}$ & 9th & 8th & 6th & 6th & $3 \mathrm{rd}$ & $1 \mathrm{st}$ \\
\hline
\end{tabular}

We can observe that the SCR connected to the occurrence of a natural disaster is considered as associated with the highest level of priority: it occupies the first position in five scenarios and the third position in the sixth scenario (when a considerably higher weight is attributed to occurrence, and lower weights are considered for criteria representing severity). This risk is indeed characterized by higher global severity and lower occurrence. In practical terms, a natural disaster could be represented, for example, by a strong wind affecting the maritime shipment and parts supplying. To mention a present occurrence, also the spread of the Covid-19 disease can be considered as a natural disaster, dangerously threatening the health of populations and with unknown repercussions on the economy of many countries. The occurrence of such a kind of risk is indeed strongly affecting production lines, since many companies worldwide are experiencing a complete stoppage of their activity. From a practical point of view, they will have to deal with difficult management challenges by finding new ways to carry out their business processes and new alternatives in terms of special delivery or similar parts. With specific relation to the automotive industry, process innovation and production line retooling are demonstrating to be crucial to face the occurred natural disaster. It seems suitable to herein cite few examples of successful production retooling in the automotive sector that are contributing to face the coronavirus emergency, such as the Italian luxury sports car manufacturer Ferrari, the world leader in its sector, who has recently converted one of its factories to the production of surgical face masks. The Italian leader automotive company FIAT is doing the same by converting one of its factories located in Asia with the aim of providing healthcare staff with suitable protection devices. The Spanish and German multinational automotive manufacturing companies Seat and Volkswagen also declared their intention to dedicate efforts in supplying respirators of the categories FFP-2 and FFP-3. The same is happening for American companies General Motors and Ford, urged by the Federal Government. In this sense, we would like to stress that making preliminary investments in increasing the flexibility of production lines reveals to be a key point for managing the risk of occurrence of natural disasters in the automotive industry. 
Moreover, the sensitivity analysis confirms that certain aspects, such as the manufacturing facilities, human resources, policies and breakdown processes and ineffective transport, have to be managed with priority.

The sensitivity analysis also confirms that management of certain risks, such as tax increases, sudden design changes and supply chain disruptions due to events of terrorism, can be postponed in time.

\section{Conclusions}

This paper deals with the topic of supply chain risk (SCR) assessment as a fundamental preliminary part of the entire supply chain management process. Starting from the analysis of the existing literature, we have elaborated a list of twenty-three risks potentially involving supply chains in the automotive industry. We claim this represents a state-of-the-art contribution in the field of complex networks, such as supply chains, to ascertain the criticalities and risks in systems engineering. To the best of our knowledge, such a classification has not been implemented before. Additionally, the risks were categorized according to their types and sources by relying on the help of a decision-making team composed of four experts in the field of supply chains.

The elaborated list was integrated into FMECA, and a new modification related to the traditional calculation of the RPN has been herein proposed. Specifically, from the three parameters traditionally used to establish priorities, we keep occurrence, and express severity through two other factors, namely dependence and cost. We also consider the factor of strategic impact in the calculation instead of the detectability, given its primary role in supply chain processes.

The calculation of the modified RPN was performed by means of the support of an integrated MCDM approach making use of AHP for calculating the weights to ponder the four factors, and fuzzy DEMATEL to evaluate the factor of dependence for each risk. We believe this approach is effective to overcome some of the criticisms expressed about the traditional RPN calculation, and also to consider uncertainty and vagueness associated with pairwise comparisons and judgments about mutual influence expressed by experts in the SC field.

According to the results achieved in the case study section, when planning interventions of prevention/mitigation, primary importance should be given to the following aspects: (1) supply chain disruptions due to natural disasters; (2) manufacturing facilities, human resources, policies and processes breakdown; and (3) inefficient transport. With relation to the first risk, we underline that production line retooling is demonstrating to be fundamental in the present times within the context of the automotive industry. The practical implication of our results in this sector is that investment in increasing production flexibility should be made as a priority preventive action. A sensitivity analysis testing the robustness of the achieved results was performed by varying the factors weights in the six possible scenarios.

The developed approach is transferable to a great variety of complex networks, industries and work-processes, to assess the criticality and risk so as to improve the management and operation in systems engineering. The approach can be applied to any other context without requiring any modification of the new introduced parameters. Indeed, we believe that the factors of "dependence" and "strategic impact" are valid for any industrial field and significant for any type of risk assessment. In terms of practical application, just the input list of risks (with the related numerical evaluations) will have to be adapted according to the specific context under analysis.

Author Contributions: Conceptualization, data curation, I.M.; methodology, software, I.M., S.C., J.I.; validation, formal analysis, investigation, resources, I.M., S.C., J.I.; writing-original draft preparation, I.M., S.C.; writing-review and editing, A.C., Z.E.F., J.I.; visualization, supervision, project administration, I.M., S.C., A.C., Z.E.F., J.I. All authors have read and agreed to the published version of the manuscript.

Funding: This research received no external funding.

Conflicts of Interest: The authors declare no conflict of interest. 


\section{References}

1. Porter, M.E. Competitive Advantage: Creating and Sustaining Superior Performance; New York Free Press: London, UK, 1985.

2. Tian, Q.; Guo, W. Reconfiguration of manufacturing supply chains considering outsourcing decisions and supply chain risks. J. Manuf. Syst. 2019, 52, 217-226. [CrossRef]

3. Munir, M.; Jajja, M.S.S.; Chatha, K.A.; Farooq, S. Supply chain risk management and operational performance: The enabling role of supply chain integration. Int. J. Prod. Econ. 2020, 227, 107667. [CrossRef]

4. Wu, Y.; Jia, W.; Li, L.; Song, Z.; Xu, C.; Liu, F. Risk assessment of electric vehicle supply chain based on fuzzy synthetic evaluation. Energy 2019, 1821, 397-411. [CrossRef]

5. Garvey, M.D.; Carnovale, S. The rippled newsvendor: A new inventory framework for modeling supply chain risk severity in the presence of risk propagation. Int. J. Prod. Econ. 2020, 228, 107752. [CrossRef] [PubMed]

6. Kern, D.; Moser, R.; Hartmann, E.; Moder, M. Supply risk management: Model development and empirical analysis. Int. J. Phys. Distrib. Logist. Manag. 2012, 42, 60-82. [CrossRef]

7. Wang, H.; Gu, T.; Jin, M.; Zhao, R.; Wang, G. The complexity measurement and evolution analysis of supply chain network under disruption risks. Chaos Solitons Fractals 2018, 116, 72-78. [CrossRef]

8. Ghoshal, S. Global strategy: An organizing framework. Strateg. Manag. J. 1987, 8, 425-440. [CrossRef]

9. Schoenherr, T.; Tummala, V.M.R.; Harrison, T.P. Assessing supply chain risks with the analytic hierarchy process: Providing decision support for the offshoring decision by a US manufacturing company. J. Purch. Supply Manag. 2008, 14, 100-111. [CrossRef]

10. Ming, X.; Yuanyuan, C.; Meng, H.; Xinkai, X.; Zhechi, Z.; Sai, L.; Shen, Q. Supply chain sustainability risk and assessment. J. Clean. Prod. 2019, 225, 857-867.

11. Curkovic, S.; Scannell, T.; Wagner, B. Using FMEA for supply chain risk management. Mod. Manag. Sci. Eng. 2013, 1, 251-265.

12. EN 60812 Standard. Analysis Techniques for System Reliability_Procedure for Failure Mode and Effects Analysis (FMEA); CEI Italian Electrotechnical Committee: Milan, Italy, 2006. Available online: https://www.saiglobal. com/pdftemp/previews/osh/iec/iec60000/60800/iec60812\%7Bed2.0\%7Den_d.pdf. (accessed on 1 April 2020).

13. Tang, C.S.; Tomlin, B. The power of flexibility for mitigating supply chain risks. Int. J. Prod. Econ. 2008, 116, 12-27. [CrossRef]

14. Ghadge, A.; Dani, S.; Kalawsky, R. Supply chain risk management: Present and future scope. Int. J. Phys. Distrib. Logist. Manag. 2012, 23, 313-339. [CrossRef]

15. Ho, W. Integrated analytic hierarchy process and its application-A literature review. Eur. J. Oper. Res. 2008, 186, 211-228. [CrossRef]

16. Saaty, T.L. The Analytic Hierarchy Process; McGraw-Hill: New York, NY, USA, 1980.

17. Asschilean, I.; Badea, G.; Giurca, I.; Naghiu, G.S.; Iloaie, F.G. Choosing the optimal technology to rehabilitate the pipes in water distribution systems using the AHP method. Energy Procedia 2017, 112, 19-26. [CrossRef]

18. Lolli, F.; Ishizaka, A.; Gamberini, R.; Rimini, B. A multicriteria framework for inventory classification and control with application to intermittent demand. J. Multi-Criteria Decis. Anal. 2017, 24, 275-285. [CrossRef]

19. Zak, J.; Kruszynski, M. Application of AHP and ELECTRE III/IV methods to multiple level, multiple criteria evaluation of urban transportation projects. Transp. Res. Procedia 2015, 10, 820-830. [CrossRef]

20. Zaidan, A.A.; Zaidan, B.B.; Al-Haiqi, A.; Kiah, M.L.M.; Hussain, M.; Abdulnabi, M. Evaluation and selection of open-source EMR software packages based on integrated AHP and TOPSIS. J. Biomed. Inform. 2015, 53, 390-404. [CrossRef]

21. Govindan, K.; Khodaverdi, R.; Vafadarnikjoo, A. Intuitionistic fuzzy based DEMATEL method for developing green practices and performances in a green supply chain. Expert Syst. Appl. 2015, 42, 7207-7220. [CrossRef]

22. Lee, H.S.; Tzeng, W.; Wang, Y.J.; Yang, S.C.; Yeih, G.H. Revised DEMATEL: Resolving the infeasibility of DEMATEL. Appl. Math. Model. 2013, 37, 6746-6757. [CrossRef]

23. Fontela, E.; Gabus, A. DEMATEL, Innovative Methods; Technical Report No. 2 1974; Structural Analysis of the World Problematique; Battelle Geneva Research Institute: Geneva, Swizterland, 1974.

24. Fontela, E.; Gabus, A. The DEMATEL Observe; Battelle Institute: Geneva, Swizterland, 1976.

25. Chang, K.-H.; Chang, Y.-C.; Lee, Y.-T. Integrating TOPSIS and DEMATEL methods to rank the risk of failure of FMEA. Int. J. Inf. Technol. Decis. Mak. 2014, 13, 1229-1257. [CrossRef] 
26. Naderikia, R.; Nazeri, A. A new fuzzy approach to identify the critical risk factors in maintenance management. Int. J. Adv. Manuf. Technol. 2017, 92, 3749-3783.

27. Liu, H.-C.; You, J.-X.; Lin, Q.-L.; Li, H. Risk assessment in system FMEA combining fuzzy weighted average with fuzzy decision-making trial and evaluation laboratory. Int. J. Comput. Integr. Manuf. 2015, 28, 701-714. [CrossRef]

28. Muhammad, N.; Cavus, N. Fuzzy DEMATEL method for identifying LMS evaluation criteria. Procedia Comput. Sci. 2017, 120, 742-749. [CrossRef]

29. Chang, K.H.; Cheng, C.H. Evaluating the risk of failure using the fuzzy OWA and DEMATEL method. J. Intell. Manuf. 2011, 22, 113-129. [CrossRef]

30. March, J.; Shapira, Z. Managerial perspectives on risk and risk taking. Manag. Sci. 1987, 33, 1404-1418. [CrossRef]

31. Blos, M.F.; Quaddus, M.; Wee, H.M.; Watanabe, K. Supply chain risk management (SCRM): A case study on the automotive and electronic industries in Brazil. Supply Chain Manag. 2009, 14, 247-252. [CrossRef]

32. Hallikas, J.; Karvonen, I.; Pulkkinen, U.; Virolainen, V.M.; Tuominem, M. Risk management processes in supplier networks. Int. J. Prod. Econ. 2004, 90, 47-58. [CrossRef]

33. Jüttner, U. Supply chain risk management: Understanding the business requirements from a practitioner perspective. Int. J. Logist. Manag. 2005, 16, 120-141. [CrossRef]

34. Teng, S.G.; Ho, S.M.; Shumar, D.; Liu, P.C. Implementing FMEA in a collaborative supply chain environment. Int. J. Qual. Reliab. Manag. 2006, 23, 179-196. [CrossRef]

35. Jüttner, U.; Peck, H.; Christopher, M. Supply chain risk management: Outlining an agenda for future research. Int. J. Logist. 2003, 6, 197-210. [CrossRef]

36. Sodhi, M.S.; Son, B.G.; Tang, C.S. Researchers' perspectives on supply chain risk management. Prod. Oper. Manag. 2012, 21,1-13. [CrossRef]

37. Trent, R.; Roberts, L. Managing Global Supply and Risk: Best Practices, Concepts, and Strategies; Ross Publishing, Inc.: Fort Lauderdale, FL, USA, 2010.

38. Bode, C.; Wagner, S.M. An empirical investigation into supply chain vulnerability. J. Purch. Supply Manag. 2006, 12, 301-312.

39. Manuj, I.; Mentzer, J.T. Global supply chain risk management strategies. Int. J. Phys. Distrib. Logist. Manag. 2008, 38, 192-223. [CrossRef]

40. Bevilacqua, M.; Ciarapica, F.E.; Marcucci, G.; Mazzuto, G. Fuzzy cognitive maps approach for analysing the domino effect of factors affecting supply chain resilience: A fashion industry case study. Int. J. Prod. Res. 2019, 1-29. [CrossRef]

41. Bevilacqua, M.; Ciarapica, F.E.; Marcucci, G.; Mazzuto, G. Conceptual model for analysing domino effect among concepts affecting supply chain resilience. Supply Chain Forum Int. J. 2018, 19, 282-299. [CrossRef]

42. Hsieh, C.Y.; Wee, H.M.; Chen, A. Resilient logistics to mitigate supply chain uncertainty: A case study of an automotive company. Sci. Iran. 2016, 23, 2287-2296. [CrossRef]

43. Lotfi, M.; Saghiri, S. Disentangling resilience, agility and leanness: Conceptual development and empirical analysis. J. Manuf. Technol. Manag. 2018, 29, 168-197. [CrossRef]

44. Marasova, D.; Andrejiova, M.; Grincova, A. Applying the heuristic to the risk assessment within the automotive industry supply chain. Open Eng. 2017, 7, 43-49. [CrossRef]

45. Pandey, A.K.; Sharma, R.K. FMEA-based interpretive structural modelling approach to model automotive supply chain risk. Int. J. Logist. Syst. Manag. 2017, 27, 395-419. [CrossRef]

46. Vujović, A.; Đorđević, A.; Gojković, R.; Borota, M. ABC classification of risk factors in production supply chains with uncertain data. Math. Probl. Eng. 2017, 2017, 4931797. [CrossRef]

47. Aven, T. The risk concept-Historical and recent development trends. Reliab. Eng. Syst. Saf. 2012, 99, 33-44. [CrossRef]

48. Bowles, J.B. An assessment of RPN prioritization in a failure modes effects and criticality analysis. In Proceedings of the Annual Reliability and Maintainability Symposium, Tampa, FL, USA, 27-30 January 2003; pp. 380-386.

49. Chang, D.S.; Sun, K.L.P. Applying DEA to enhance assessment capability of FMEA. Int. J. Qual. Reliab. Manag. 2009, 26, 629-643. [CrossRef]

50. Chin, K.S.; Wang, Y.M.; Poon, G.K.K.; Yang, J.B. Failure mode and effects analysis using a group-based evidential reasoning approach. Comput. Oper. Res. 2009, 36, 1768-1779. [CrossRef] 
51. Chang, B.; Chang, C.-W.; Wu, C.-H. Fuzzy DEMATEL method for developing supplier selection criteria. Expert Syst. Appl. 2011, 38, 1850-1858. [CrossRef]

52. Zhang, Z.F.; Chu, X.N. Risk prioritization in failure mode and effects analysis under uncertainty. Expert Syst. Appl. 2011, 38, 206-214. [CrossRef]

53. Zhang, Y.F.; Zhou, R.B.; Yang, J.M.; Zhang, Z. Application of FMEA-FTA method in fault diagnosis of tracked vehicle. Adv. Mater. Res. 2014, 940, 112-115. [CrossRef]

54. Liu, H.-C. FMEA using uncertainty theories and MCDM methods. In FMEA Using Uncertainty Theories and MCDM Methods; Springer: Singapore, 2016; pp. 13-27.

55. Liu, H.-C.; Liu, L.; Bian, Q.H.; Lin, Q.L.; Dong, N.; Xu, P.C. Failure mode and effects analysis using fuzzy evidential reasoning approach and grey theory. Expert Syst. Appl. 2011, 38, 4403-4415. [CrossRef]

56. Liu, H.C.; Liu, L.; Liu, N.; Mao, L.X. Risk evaluation in failure mode and effects analysis with extended VIKOR method under fuzzy environment. Expert Syst. Appl. 2012, 39, 12926-12934. [CrossRef]

57. Liu, Y.; Yuan, Y.; Fan, Z.P. A FTA-based method for risk decision making in emergency response. Comput. Oper. Res. 2014, 42, 49-57. [CrossRef]

58. Kutlu, A.C.; Ekmekçioğlu, M. Fuzzy failure modes and effects analysis by using fuzzy TOPSIS-based fuzzy AHP. Expert Syst. Appl. 2012, 39, 61-67. [CrossRef]

59. Chang, C.L.; Liu, P.H.; Wei, C.C. Failure mode and effects analysis using grey theory. Integr. Manuf. Syst. 2001, 12, 211-216. [CrossRef]

60. Bevilacqua, M.; Braglia, M.; Gabbrielli, R. Monte Carlo simulation approach for a modified FMECA in a power plant. Qual. Reliab. Eng. Int. 2000, 16, 313-324. [CrossRef]

61. Debo, L.G.; Lai, G.; Sycara, K. Sharing inventory risk in supply chain: The implication of financial constraint. Omega 2009, 37, 811-825.

62. Carpitella, S.; Certa, A.; Izquierdo, J.; La Fata, C.M. A combined multi-criteria approach to support FMECA analyses: A real-world case. Reliab. Eng. Syst. Saf. 2018, 169, 394-402. [CrossRef]

63. Saaty, T. A scaling method for priorities in hierarchical structures. J. Math. Psychol. 1977, 15, $234-281$. [CrossRef]

64. Mahmoudi, S.; Jalali, A.; Ahmadi, M.; Abasi, P.; Salari, N. Identifying critical success factors in Heart Failure Self-Care using fuzzy DEMATEL method. Appl. Soft Comput. 2019, 84, 105729. [CrossRef]

65. Meyer, C. Matrix Analysis and Applied Linear Algebra; Society for Industrial and Applied Mathematics, 3600 University City Science Center: Philadelphia, PA, USA, 2000; ISBN 978-0-89871-454-8.

66. Sara, J.; Stikkelman, R.M.; Herder, P.M. Assessing relative importance and mutual influence of barriers for CCS deployment of the ROAD project using AHP and DEMATEL methods. Int. J. Green Gas Control 2015, 41, 336-357. [CrossRef]

(C) 2020 by the authors. Licensee MDPI, Basel, Switzerland. This article is an open access article distributed under the terms and conditions of the Creative Commons Attribution (CC BY) license (http://creativecommons.org/licenses/by/4.0/). 